\title{
Drug-Induced Interstitial Lung Disease: A Systematic Review
}

\author{
Sarah Skeoch ${ }^{1,2}$, Nicholas Weatherley ${ }^{3}$, Andrew J. Swift ${ }^{3}$, Alexander Oldroyd ${ }^{1}$, \\ Christopher Johns ${ }^{3}$, Conal Hayton ${ }^{4}$, Alessandro Giollo ${ }^{5,6}{ }^{\circ}$, James M. Wild ${ }^{3}$, \\ John C. Waterton ${ }^{7,8}{ }^{\oplus}$, Maya Buch ${ }^{5}$, Kim Linton ${ }^{9}{ }^{-}$, Ian N. Bruce ${ }^{1,10}$, Colm Leonard ${ }^{4}$, \\ Stephen Bianchi ${ }^{11}$ and Nazia Chaudhuri ${ }^{4, *}$
}

1 Arthritis Research UK Centre for Epidemiology, Division of Musculoskeletal and Dermatological Sciences, School of Biological Sciences, Faculty of Biology Medicine \& Health, University of Manchester, Manchester Academic Health Sciences Centre, Manchester M13 9PL, UK; sarah.skeoch@manchester.ac.uk (S.S.);

Alexander.Oldroyd@manchester.ac.uk (A.O.); Ian.Bruce@manchester.ac.uk (I.N.B.)

2 Royal National Hospital for Rheumatic Diseases, Royal United Hospitals Bath NHS Foundation Trust, Bath BA1 1RL, UK

3 Department of Infection, Immunity \& Cardiovascular Disease, University of Sheffield, Sheffield S10 2TN, UK; nickweatherley@doctors.org.uk (N.W.); A.J.Swift@sheffield.ac.uk (A.J.S.); c.johns@sheffield.ac.uk (C.J.); J.M.Wild@sheffield.ac.uk (J.M.W.)

4 North West Lung Centre, Manchester University NHS Foundation Trust, Manchester Academic Health Science Centre, Manchester M6 8HD, UK; conalhayton@doctors.org.uk (C.H.);

Colm.Leonard@nice.org (C.L.)

5 Leeds Institute of Rheumatic and Musculoskeletal Medicine, NIHR Leeds Biomedical Research Centre, University of Leeds, Leeds LS2 9JT, UK; A.Giollo@leeds.ac.uk (A.G.); M.Buch@leeds.ac.uk (M.B.)

6 Rheumatology Unit, Department of Medicine, University of Verona, 37134 Verona, Italy

7 Bioxydyn Limited, Rutherford House, Manchester Science Park, Manchester M15 6SZ, UK; john.waterton@manchester.ac.uk

8 Centre for Imaging Sciences, Division of Informatics Imaging \& Data Sciences, School of Health Sciences, Faculty of Biology Medicine \& Health, University of Manchester, Manchester Academic Health Sciences Centre, Manchester M13 9PL, UK

9 Division of Cancer Sciences, School of Medical Sciences, Faculty of Biology Medicine and Health, University of Manchester, Manchester Academic Health Sciences Centre, Manchester M13 9PL, UK;

Kim.Linton@manchester.ac.uk

10 The Kellgren Centre for Rheumatology, NIHR Manchester Biomedical Research Centre, Manchester University NHS Foundation Trust, Manchester Academic Health Science Centre, Manchester M6 8HD, UK

11 Academic Directorate of Respiratory Medicine, Sheffield Teaching Hospitals NHS Foundation Trust, Sheffield S10 2JF, UK; Stephen.Bianchi@sth.nhs.uk

* Correspondence: nazia.chaudhuri@nhs.net; Tel.: +44-161-998-7070

Received: 19 August 2018; Accepted: 8 October 2018; Published: 15 October 2018

\begin{abstract}
Background: Drug-induced interstitial lung disease (DIILD) occurs as a result of numerous agents, but the risk often only becomes apparent after the marketing authorisation of such agents. Methods: In this PRISMA-compliant systematic review, we aimed to evaluate and synthesise the current literature on DIILD. Results: Following a quality assessment, 156 full-text papers describing more than 6000 DIILD cases were included in the review. However, the majority of the papers were of low or very low quality in relation to the review question (78\%). Thus, it was not possible to perform a meta-analysis, and descriptive review was undertaken instead. DIILD incidence rates varied between 4.1 and 12.4 cases/million/year. DIILD accounted for 3-5\% of prevalent ILD cases. Cancer drugs, followed by rheumatology drugs, amiodarone and antibiotics, were the most common causes of DIILD. The radiopathological phenotype of DIILD varied between and within agents, and no typical radiological pattern specific to DIILD was identified. Mortality rates of over 50\% were reported in some studies. Severity at presentation was the most reliable predictor of mortality.
\end{abstract}


Glucocorticoids (GCs) were commonly used to treat DIILD, but no prospective studies examined their effect on outcome. Conclusions: Overall high-quality evidence in DIILD is lacking, and the current review will inform larger prospective studies to investigate the diagnosis and management of DIILD.

Keywords: drug-induced interstitial lung disease; pulmonary toxicity; drug-induced pneumonitis

\section{Introduction}

Drug-induced interstitial lung disease (DIILD) occurs when exposure to a drug causes inflammation and eventually fibrosis of the lung interstitium. Over 350 drugs may cause DIILD, but liability is often not recognised until late in drug development, or after launch. New causative drugs are regularly identified, with over 1300 drugs, procedures or substances reported to cause respiratory problems on the comprehensive Pneumotox website (www.pneumotox.com). DIILD is a recognised subtype of diffuse parenchymal lung diseases according to the American Thoracic Society/European Respiratory Society (ATS/ERS) classification [1], but clinical, pathological and radiological features are rarely specific and difficult to distinguish from other interstitial pneumonias. Moreover, the clinical phenotype, imaging and histopathology patterns vary significantly between drugs and between patients on the same drug. DIILD is consequently a diagnosis of exclusion, and this poses unique challenges for the treating physician and for the study of DIILD in both epidemiological and drug development settings.

DIILD is diagnosed on the basis of clinical, physiological and radiological findings consistent with ILD; a temporal relationship between onset of symptoms and drug exposure; absence of another more likely cause, e.g., infection, pulmonary oedema, radiation-induced lung injury, progression of the underlying disease; and improvement upon withdrawal of the suspected causative agent with or without corticosteroid therapy and, in some cases, deterioration upon re-challenge. An internationally agreed severity classification is used in clinical trials (Table 1) [2].

Table 1. Grading of drug-induced interstitial lung disease (DIILD) based on the National Cancer Institute Common Terminology Criteria for Adverse Events [2].

\begin{tabular}{ll}
\hline Grade 1 (mild) & Asymptomatic, radiographic findings only \\
Grade 2 (moderate) & Symptomatic, not interfering with activities of daily living \\
Grade 3 (severe) & Symptomatic, interfering with activities of daily living or oxygen indicated \\
Grade 4 (life-threatening or disabling) & Life-threatening, or ventilator support required \\
Grade 5 (fatal) & \\
\hline
\end{tabular}

Drugs and patterns of disease are catalogued in the International Database "Pneumotox" (www. pneumotox.com). However, there is no detailed overall picture of the incidence, phenotype and clinical course of DIILD. The Translational Imaging in Drug Safety Initiative (TRISTAN) consortium is designing prospective studies to develop sensitive and specific biomarkers in patients with DIILD (http:/ / www.imi-tristan.eu). The aim of this systematic review is to summarise the current knowledge of DIILD as a useful guide to clinicians and to inform the TRISTAN studies.

\section{Methods}

We conducted a systematic review of observational studies in accordance with the Preferred Reporting Items for Systematic Reviews and Meta-Analyses consensus guidelines (PRISMA) [3], with the aims of: (1) determining the incidence and prevalence of DIILD, (2) identifying common causative drugs, (3) identifying risk factors for DIILD, (4) comparing imaging and non-imaging investigations for assessment and diagnosis of DIILD, (5) assessing the prevalence of DIILD subtypes, (6) measuring the impact of glucocorticoid therapy on outcomes and (7) defining the prognosis of DIILD. We searched 
Medline, Embase and The Cochrane Register of Controlled Trials in May 2017 using the Medical Subject Headings (MESH) and keyword searches detailed in Figure 1. The following exclusion criteria were applied: studies not in English language, non-human studies, sample size of less than 10, DIILD related to non-licensed drugs and chemicals, e.g., alcohol or organophosphates. Two authors independently screened the titles and abstracts for eligibility. In circumstances where it was not clear from the abstract that the study was eligible, the paper was included in the full-text review. Any disagreements regarding abstract inclusion were resolved by a third independent reviewer. Additional papers were also identified through grey (manual) searches. Full texts of eligible papers were obtained and assessed for inclusion in duplicate, with two reviewers allocated to each question. In the case of overlap between articles reporting the same cohort, we included the study with the largest cohort. The quality of evidence and risk of bias were assessed using the Grading Recommendations Assessment and Development Evidence (GRADE) criteria with supporting guidance from the Cochrane website [4]. Data were extracted using the Population, Intervention, Comparison, Outcome (PICO) framework and included title, year of publication, study design, sample size, study population, patient characteristics, intervention and comparator (where applicable), outcomes, funding and conclusions. The study was prospectively registered on the PROSPERO website (registration number: CRD42017071276). Data were evaluated for inclusion in a meta-analysis based on quality and bias, and, if excluded, descriptive synthesis was undertaken.

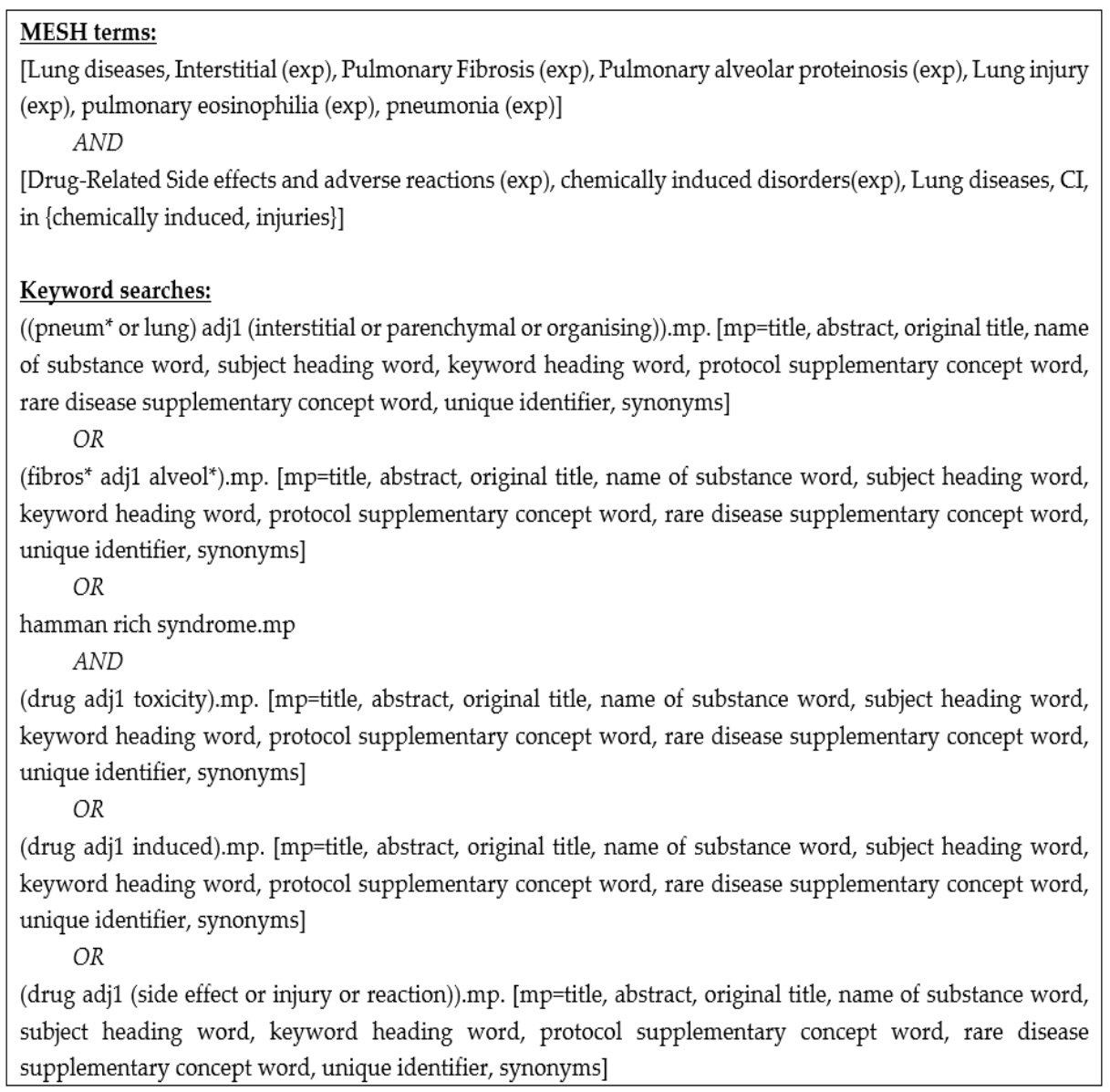

Figure 1. Search terms used in Medline, Embase and Cochrane Register of Controlled Trials.

\section{Results}

After de-duplication, we reviewed 1694 titles and abstracts; from these, we included $185(10.9 \%)$ in a full-text review (Figure 2). A further 66 articles were excluded after full review, and 37 were included in grey searches, providing a total of 156 articles eligible for inclusion. The most common 
reasons for exclusion of full-text papers were that the study provided no information relevant to the study questions (e.g., described all adverse drug events without specific information on DIILD) $(n=$ $24)$, it took the form of a narrative review $(n=20)$ or the sample size was less than $10(n=12)$. Of those where sample size was less than 10, only one drug was not described in the other included papers (hydroxyurea). Potential biases and the quality of included articles are described in Figure 3. The majority were low or very low quality $(78 \%)$, and $90 \%$ had a high risk of bias, mainly due to significant limitations in design, poor precision and indirectness of the study population. Another major limitation was the lack of standardised case definition for DIILD; some studies used physician-reported diagnosis, others used radiological evidence of ILD to define cases without an assessment of clinical characteristics or exclusion of infection, and workup to exclude another competing diagnosis was not stated, minimal or absent. In many studies, a significant proportion of subjects were asymptomatic. A number of post-marketing studies attempted to address this with an expert panel case review and verification process. However, the overall lack of standardised case definition and a paucity of independent case verification hampered any quantitative data synthesis.

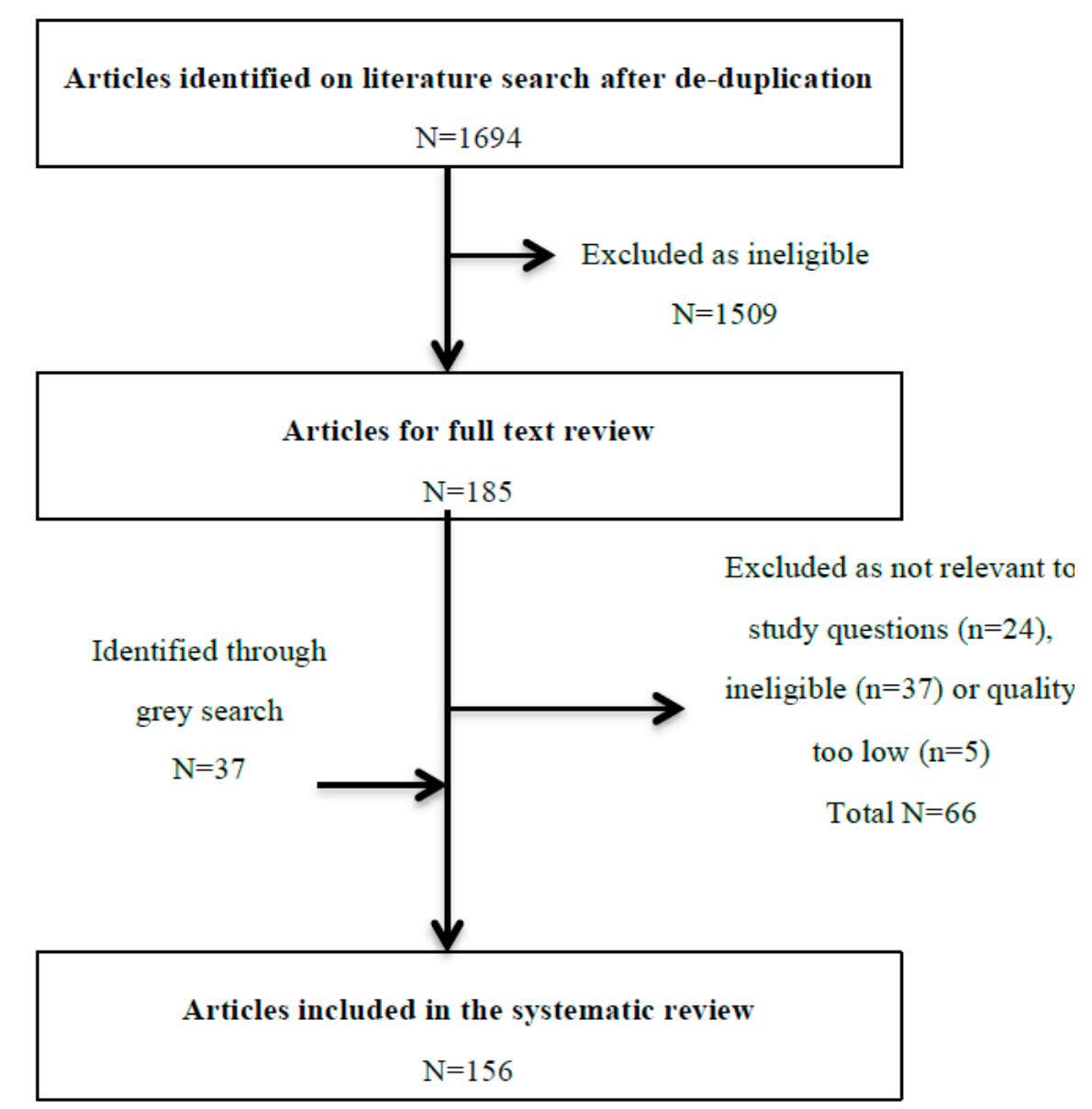

Figure 2. Flow diagram of the review process from abstract review to final inclusion. In total, these 156 articles report approximately 6200 patients with confirmed or suspected DIILD, which was fatal in around $672 / 2647(25.4 \%)$ cases.

We also noted a geographical bias, with more than one-third of the studies (mainly large post-marketing registers) being reported from Japan. A higher prevalence of reported ILD compared to the West has previously been noted in Japanese populations; however, much of this has been suggested to be artefactual due to coding and spontaneous reporting practices, rather than biological reasons [5]. The Proportional Reporting Ratio method was not used [6]. 
Due to the overall poor quality of evidence, meta-analyses for individual questions were not possible, and a descriptive review was subsequently undertaken.
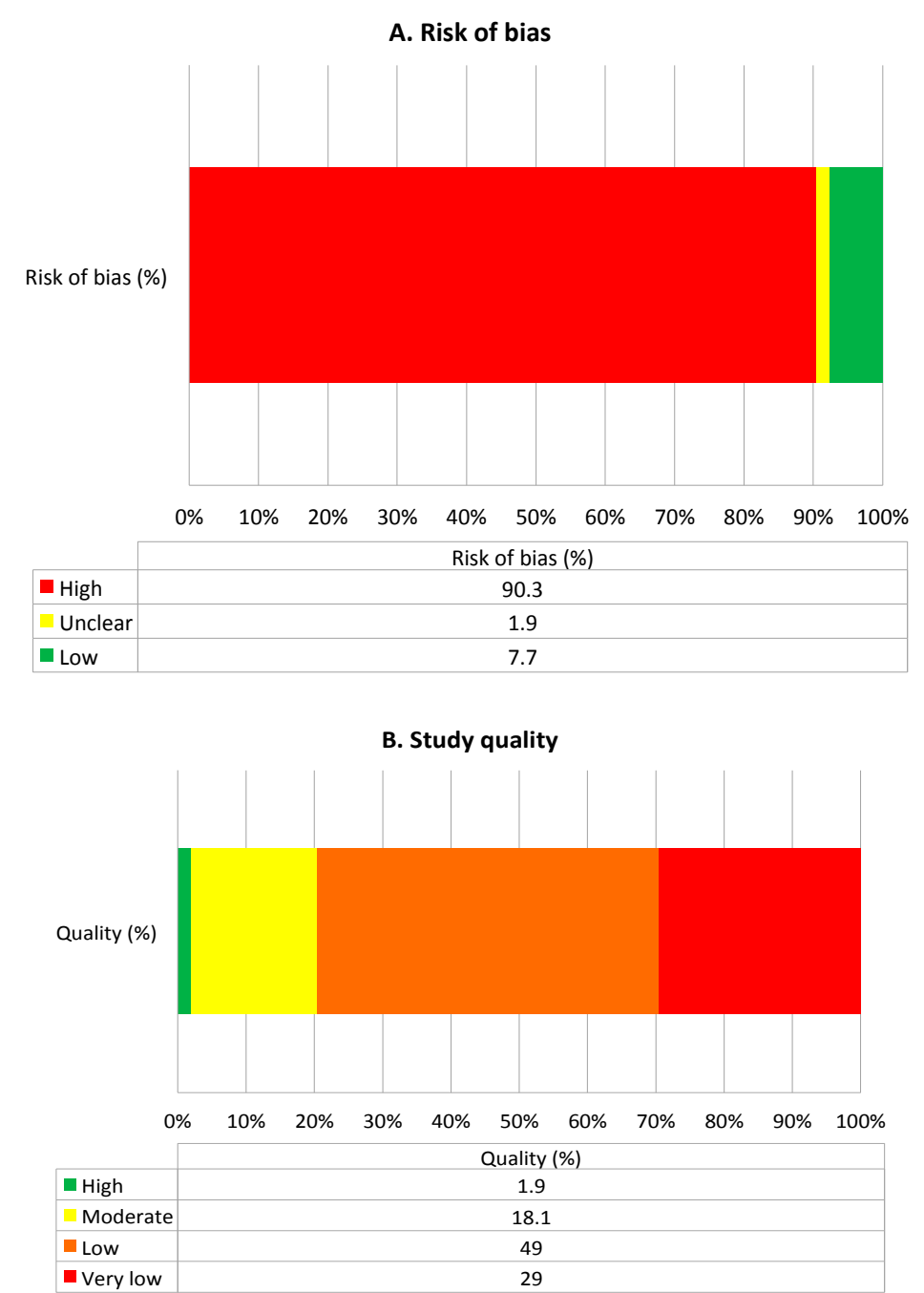

Figure 3. Summary of quality and bias, as assessed using the Grading Recommendations Assessment and Development Evidence (GRADE) method [4]. (A) Summarises risk of bias and (B) summarises quality of included studies.

\subsection{Incidence and Prevalence}

The reported incidence of DIILD for individual drugs ranged from $<1 \%$ to almost $60 \%$ (Table 2 ). Many studies relied on spontaneous physician or administrative reporting and are susceptible to reporting bias for positive cases.

At a population level, a study from the Clinical Practice Research Database (UK) between 1997 and 2008 reported an incidence of 4.1 per million per annum [7] based on 128 patients with drug- $(n=$ 22) or radiation-induced ( $n=106)$ ILD. This is likely to be a significant underestimate, considering the case definitions they used and the primary care nature of the cohort. Furthermore, since these figures were published, there has been a significant expansion of new oncology drugs with a high rate of DIILD (www.pneumotox.com). A more recent study in a county within Greater Paris estimated the incidence of all ILD cases at 19.4 per 100,000 per year based on both primary and secondary care data [8]. DIILD accounted for $6.4 \%$ of incident cases, suggesting a rate of 12.4 cases per million per year. However, the authors acknowledged that the population was not representative of the demographic structure of the French general population. A few studies also examined rates of DIILD within ILD 
populations [8-11]. Four ILD cohorts of 848, 237, 460 and 431 cases of ILD estimated the prevalence of DIILD to be $3 \%, 3 \%, 2.6 \%$ and $5 \%$, respectively [ $8-11]$.

\subsection{Common Causative Drugs}

We identified six single-centre studies that comprehensively reported DIILD rates for individual drugs in unselected DIILD cohorts [12-17]. Not all studies reported DIILD as the primary objective: five were retrospective studies and four were from a single region (Japan). Cancer drugs were the leading cause of DIILD in most studies, accounting for $23-51 \%$ of cases, followed by disease-modifying anti-rheumatic drugs (DMARDs) (6-72\%), antibiotics (6-26\%), non-steroidal anti-inflammatory agents (NSAIDs) (0-23\%), psychiatric medications (0-9\%) and anti-arrhythmic agents (0-9\%). In the Flanders ILD registry, amiodarone followed by nitrofurantoin were the most common causes [10]. Table 1 summarises the incidence and mortality rates for DIILD studies relating to specific agents or drug classes. Consistent with results from unselected DIILD cohort studies, cancer drugs accounted for the majority of drug-specific published studies identified in the initial search $(n=37)$, followed by DMARDs $(n=12)$, cardiology medications $(n=10)$ and antibiotics $(n=7)$.

\subsubsection{Cancer Therapy}

Identifying specific causative agents is challenging in oncology when drugs are given in combination regimens, or in association with thoracic radiotherapy, which is independently associated with lung fibrosis. The most common individual cancer drugs causing DIILD were identified as bleomycin, gemcitabine, epidermal growth factor receptor (EGFR)-directed therapies, mechanistic target of rapamycin protein (MTOR) inhibitors and immune checkpoint inhibitors. Methotrexate, which is used for the treatment of cancer as well as rheumatological conditions, was also identified.

\section{Bleomycin}

Bleomycin, used predominantly to treat Hodgkin's lymphoma and germ cell tumours, causes lung injury via immune-mediated and direct toxic effects $[18,19]$. The reported risk is $6.8-21 \%$, with an associated mortality rate of up to $48 \%$ [18-23]. The clinical presentation of bleomycin lung injury is highly variable but can be asymptomatic. Up to $39 \%$ of cases are detected on imaging alone [22,23]. Pulmonary physiology changes are common and include an early reduction in diffusing capacity of the lung for carbon monoxide $\left(\mathrm{D}_{\mathrm{LCO}}\right)$ followed by changes in forced vital capacity (FVC), which correlates with symptomatic deterioration [18,22].

DIILD can occur at any time during treatment [18]. A study in germ cell tumour patients treated with high-dose bleomycin reported a median time from bleomycin initiation to DIILD of 4.2 months [23]. In this study, cumulative doses $>300,000$ international units were associated with a 3.5-fold increased risk of DIILD. Idiosyncratic reactions at low doses early in the treatment course are also less commonly described $[18,23]$. Recent advances in positron emission tomography-directed omission of bleomycin in selected patients with Hodgkin's lymphoma have been associated with a significant reduction in pulmonary toxicity [24].

\section{Gemcitabine}

Gemcitabine is used to treat a range of cancers, including non-small cell lung cancer (NSCLC), pancreatic cancer and breast cancer [13,25-28]. The risk of DIILD is highest when used in combination with other agents, especially bleomycin, erlotinib and taxanes [25,26,28-31], with reported incidence rates of $1-20 \%$. Mortality rates are generally low [26-28,32] except in severe cases requiring hospitalisation, where mortality reaches $20 \%$ [30]. In contrast to bleomycin, the dose relationship and timing of onset are less consistent $[13,26,29]$.

A nationwide retrospective database study in Japan identified 428 cases of DIILD in 25,924 gemcitabine-treated patients [30]. The median time of onset was 65 days and the cumulative incidence 
was $1.1 \%, 1.5 \%$ and $1.9 \%$ at 3,6 and 12 months. The crude incidence rates were similar after monotherapy $(1.7 \%)$ and combination therapy $(1.6 \%)$.

Epidermal Growth Factor Receptor (EGFR)-Targeted Agents

EGFR-targeted agents include small molecule receptor tyrosine kinase inhibitors (RTKIs) and monoclonal antibodies licenced for treatment of NSCLC, breast cancer and colorectal cancer [33,34]. The reported incidence of DIILD for the EGFR-RTKIs gefitinib and erlotinib is 1.2-1.6\%, with an associated mortality rate of $22.8 \%$ [35,36]. DIILD following EGFR-RTKIs appears to be an early event, with studies of gefitinib and erlotinib reporting the highest incidence within 4 weeks of starting treatment $[34,37]$.

In Japanese post-marketing surveillance studies, the incidence of DIILD with EGFR-directed monoclonal antibodies, such as panitumumab and cetuximab, was $1.3 \%$ and $1.2 \%$, respectively, with a broad time to onset (median 101 days, range 17-431) [33,38]. Another study reported a median onset of 113 days (range 1-559) following the first dose of panitumumab, with 11/39 cases occurring after 6 months of therapy [39]. Notably, many patients in this series also received treatment in combination with other agents associated with DIILD risk. A single study in Japan reported mortality rates of $41.6 \%$ and 51.3\% for cetuximab- and panitumumab-related DIILD, respectively [33].

Mechanistic Target of Rapamycin Protein (MTOR) Inhibitors

MTOR inhibitors are used predominantly to treat renal cell cancers and neuroendocrine tumours, and as anti-rejection agents in solid organ transplantation [40-45]. Sirolimus, temsirolimus and everolimus have all been associated with pulmonary toxicity [45-47]. A meta-analysis of 2233 everolimus-treated cancer patients in five clinical trials reported a DIILD incidence of $10.4 \%$ (all grades) and 2.4\% (grade 3-4). Mortality data were not reported, and no associations with treatment duration, gender or cancer outcomes were observed [46]. Cases were observed in not only Japanese centres but also Western countries.

Post hoc analysis of computerised tomography (CT) data from clinical trials of temsirolimus and everolimus found a significantly higher incidence of radiographic changes consistent with DIILD (everolimus radiographic $53.9 \%$ vs. clinical $13.5 \%$; temsirolimus $29 \%$ vs. $6 \%$ ) $[42,45,47]$.

In organ transplant recipients, variable incidence rates ranging from $2.8 \%$ to $12.7 \%$ have been reported in observational studies $[41,48,49]$.

Immune Checkpoint Inhibitors

Checkpoint inhibitors of programmed cell death 1 (PD-1) and its ligands (PD-L1 and PD-L2) and cytotoxic lymphocyte antigen protein 4 (CTLA-4) are an emerging class of agents currently licensed in metastatic melanoma, NSCLC and Hodgkin's lymphoma [50-52]. Immune-mediated reactions are well recognised [50]. A meta-analysis of clinical trials of PD-1 and PD-L1 inhibitors highlighted a DIILD incidence rate of 3.6\% for PD-1 inhibitors (nivolumab, pembrolizumab) and 1.1\% for PD-L1 inhibitors (avelumab and durvalumab) [52,53]. The incidence rate, severity and mortality of DIILD were all higher for PD-1 inhibitors compared with PD-L1 inhibitors, with a DIILD mortality rate of $8 \%$. No association with dose or duration of treatment was observed [52].

Another observational study of 1826 cancer patients treated with checkpoint inhibitors reported a DIILD incidence rate of 3.5\% [51], and a mortality rate of 9.4\% for DIILD cases, which is similar to clinical trial data. Time to onset ranged from 0.2 to 27.4 months, with $42 \%$ occurring within 2 months of starting treatment. When used in combination therapy, the rates of DIILD were increased compared to single-agent use [54].

\subsubsection{Rheumatological Therapy}

In rheumatology, analyses of DIILD are hampered by a background prevalence of ILD, especially in rheumatoid arthritis (RA). Furthermore, many DMARDs are immunosuppressive and associated 
with an increased risk of opportunistic infection, providing challenges in the differential diagnosis of worsening respiratory symptoms.

Methotrexate (MTX)

MTX is a mainstay agent in rheumatology and for the treatment of lymphomas and sarcomas. The incidence of DIILD in RA patients receiving low-dose MTX has been reported as $0.3-2.1 \%[55,56]$ Two meta-analyses compared rates of DIILD following MTX to other DMARDS in RA and non-RA inflammatory diseases [55,57]. In RA, the DIILD rate with MTX exposure was $0.28 \%(13 / 4544)$ compared to $0 / 4040$ for other DMARDs (relative risk $(95 \% \mathrm{CI})=7.81(1.76-34.72))$ [55]. In the non-RA population, no increased risk was seen in MTX-treated patients [57]. Interestingly, no events were reported after 2002 in the RA meta-analysis, suggesting potential reporting bias or historic over-estimation of risk [55].

MTX-induced DIILD has a variable time and rate of onset and is not apparently dose-dependent $[56,58,59]$. In one study, $48 \%$ of cases developed within 32 weeks of treatment initiation [60]. Kremer et al. noted a mean time to onset of 23 days (range 3-112) [61]. Others, however, noted cases occurring up to 4 years after starting treatment, or after treatment cessation [60]. DIILD has also been reported to recur in approximately one-third of re-challenged cases $[60,61]$ and carries a high mortality (10-30\%) [59-61].

Leflunomide

Most reported data are from Japan. In one post-marketing surveillance study of 5045 Japanese patients taking leflunomide, new ILD occurred in 1.2\%, and pre-existing ILD deteriorated in 5.7\% of cases [62]. Most patients presented within 20 weeks of treatment initiation in one study [63]. Leflunomide-related mortality was $19 \%$ and $41 \%$ in two studies [63,64]. In a nested case-control study, Suissa et al. noted significant channelling bias which may explain some of the increased risk with leflunomide [65]. However, use of a loading dose and low body weight were significantly associated with DIILD, suggesting leflunomide toxicity $[62,65]$. Pre-existing ILD, smoking and prior MTX use have also been reported to increase DIILD rates for leflunomide [62,65]. Following a medical alert advising against drug loading and caution in patients with low body weight or pre-existing ILD, the incidence of ILD was reported to have reduced from $1.46 \%$ to $0.63 \%$ [62]. Conway et al. found no increased rate of adverse pulmonary reactions from leflunomide in a meta-analysis of clinical trials [66].

\section{Biological DMARDs}

Numerous cases of suspected DIILD associated with anti-tumour necrosis factor (TNF) agents have been published, although definitive evidence of causation remains controversial [67]. Post-marketing surveillance data from Japan reported an incidence rate of $0.6 \%$ for new or progressive ILD in patients treated with anti-TNF therapy [68]. This study did not have a control arm. Cohort studies have not demonstrated a difference in rates of incident ILD between patients treated with anti-TNF agents and other types of DMARD, but there are no observational studies which compare rates of DIILD [69,70]. In a review of published case reports, 15/52 (29\%) patients with 'DIILD' on anti-TNF therapy died during follow-up, with 70\% of deaths occurring within 5 weeks of symptom onset [71]. Mortality was highest in older patients, those with pre-existing ILD or those receiving concomitant immunosuppression. Two systematic reviews highlighted cases of potential DIILD associated with other biologic DMARDs, including tocilizumab (an interleukin 6 inhibitor) and rituximab [67,72]. Three systematic reviews included published cases of rituximab-induced ILD ranging from 7 to 45 cases [72-74]. The majority of cases were oncology patients presenting with acute or subacute ILD around the fourth cycle of treatment. Case fatality ranged between $18 \%$ and $37.5 \%$ [72-74]. 


\subsubsection{Other Drug Classes}

Antibiotics

Nitrofurantoin is commonly used for the treatment and prophylaxis of urinary tract infections. DIILD accounts for $16-48 \%$ of nitrofurantoin-related adverse events reported in registry studies $[75,76]$. In a Swedish registry study of 447 nitrofurantoin-related DIILD, almost 90\% were acute reactions [76]. The hospitalisation rate was $75 \%$ and mortality rates were $0.5 \%$ and $8 \%$, respectively, for patients with acute lung reactions and chronic interstitial pneumonia [76].

An acute pulmonary reaction can occur within days of initiation, or within hours if there has been previous nitrofurantoin exposure [77]. The underlying mechanism is believed to be an acute hypersensitivity reaction, and most cases resolve quickly [77]. Chronic interstitial pneumonia is a rarer presentation mimicking pulmonary fibrosis [75-77], and is more common in patients on long-term prophylaxis [76]. Santos et al. performed a case-control study comparing DIILD with nitrofurantoin use compared to other antibiotics [78]. Overall, the relative risk (RR) of DIILD was not increased for nitrofurantoin. The absolute risk was higher for chronic compared to acute nitrofurantoin therapy (RR 1.53 chronic vs. acute use, $p<0.05$ ), and for older patients (age $>85$ relative risk 1.99 for age 85 vs. $<85$, $p<0.05)$.

Regarding other antibiotics, daptomycin-an antibiotic usually reserved for life-threatening Gram-positive bacteria-has been associated with a risk of eosinophilic DIILD. In a retrospective study, 3/102 daptomycin-treated patients developed DIILD with eosinophilia [78]. A review of the Food and Drug Administration (FDA) pharmacovigilance database identified 7 definite, 23 probable and 38 possible cases of daptomycin-induced eosinophilic pneumonias between 2004 and 2010 [79]. All patients in this series recovered.

\section{Amiodarone}

Amiodarone is one of the most common causes of DIILD in registries [10], with a reported incidence of $1.2-8.8 \%$ [ $80-84$ ] and mortality of 3-37\% [80-84]. A retrospective study of 500 patients treated with amiodarone in Japan identified 40 patients (8\%) with DIILD occurring during a mean follow-up of 48 months [85]. The cumulative incidence at 1,3 and 5 years was $4.2 \%, 7.8 \%$ and $10.6 \%$, respectively, with an estimated annual incidence of $2.1 \%$. Patients most commonly present with subacute DIILD [86,87]; however, an acute, frequently fatal form can occur [80]. One study evaluating 90-day outcomes in patients hospitalised for amiodarone-associated DIILD reported a $37 \%$ mortality rate with a median time to death of 17 days. Symptomatic recovery in survivors occurred over a median of 36 months, with improvement in radiological features of alveolitis but a high rate of fibrosis $(66 \%)$.

Cumulative dose is an important risk factor for amiodarone-related DIILD, and the combination of high doses over longer periods is more strongly associated with DIILD than dose or duration alone [88]. 
Table 2. Summary of specific classes or agents associated with DIILD identified from literature review of lung disease.

\begin{tabular}{|c|c|c|c|c|c|c|c|c|}
\hline Drug/Class & Number of Studies & Quality & Study Design & Patient Population & $\begin{array}{l}\text { Sample Size } \\
\text { (Range) }\end{array}$ & $\begin{array}{l}\text { Case Definition } \\
\text { of DIILD }\end{array}$ & $\begin{array}{l}\text { Estimated } \\
\text { Incidence } \\
\text { (Range) }\end{array}$ & $\begin{array}{c}\text { Estimated } \\
\text { Mortality in } \\
\text { Those with } \\
\text { DIILD (Range) }\end{array}$ \\
\hline \multicolumn{9}{|c|}{ Cancer Therapies } \\
\hline $\begin{array}{l}\text { Bleomycin } \\
\text { [18-24] }\end{array}$ & 7 & $\begin{array}{l}\text { Moderate }=3 \\
\text { Low }=3 \\
\text { Very low }=1\end{array}$ & $\begin{array}{c}\text { Meta-analysis }=2 \\
\text { Observational studies }=5\end{array}$ & $\begin{array}{c}\text { Various cancers (1 } \\
\text { meta-analysis in ovarian sex } \\
\text { cord stromal tumours and } 1 \text { in } \\
\text { all cancer RCT data) }\end{array}$ & 22-1147 & variable & $\begin{array}{c}\text { Meta-analyses: } \\
6.8-15 \% \\
\text { Other studies: } \\
6.8-21 \% \\
\end{array}$ & $\begin{array}{c}\text { Meta-analyses: } \\
8.1-23 \% \\
\text { Other studies: } \\
0-48 \% \\
\end{array}$ \\
\hline $\begin{array}{l}\text { Gemcitabine } \\
{[13,25-32]}\end{array}$ & 9 & $\begin{array}{l}\text { Moderate }=2 \\
\text { Low }=6 \\
\text { Very low }=1\end{array}$ & $\begin{array}{c}\text { Meta-analysis }=2 \\
\text { Clinical trial }=3 \\
\text { Observational }=4\end{array}$ & $\begin{array}{l}\text { Cancer (predominantly } \\
\text { pancreatic and non-small cell } \\
\text { lung cancer but also others) }\end{array}$ & $\begin{array}{l}\text { Meta-analysis: } \\
\text { 1308-1742 } \\
\text { Others: } 26-2440\end{array}$ & variable & $1.1-3.9 \%$ & $0-22 \%$ \\
\hline \multicolumn{9}{|c|}{ Epidermal growth factor receptor-targeted therapies (EGFR) } \\
\hline $\begin{array}{l}\text { Erlotinib } \\
{[34-36,89,90]}\end{array}$ & 5 & $\begin{array}{l}\text { Moderate }=2 \\
\text { Low }=3\end{array}$ & $\begin{array}{l}\text { Meta-analysis }=2 \\
\text { Post marketing } \\
\text { surveillance }=2 \\
\text { Observational }=1\end{array}$ & Non-small cell lung cancer & 341-9909 & variable & $0.9-5.9 \%$ & $31-45 \%$ \\
\hline Gefitinib [34-37] & 4 & $\begin{array}{l}\text { Moderate }=2 \\
\text { Low }=2\end{array}$ & $\begin{array}{l}\text { Meta-analysis }=2 \\
\text { Post marketing } \\
\text { surveillance }=2\end{array}$ & $\begin{array}{l}\text { Non-small cell lung, breast and } \\
\text { colorectal cancer }\end{array}$ & $70-5468$ & variable & $1.9-3.5 \%$ & $18-44 \%$ \\
\hline $\begin{array}{c}\text { Panitumumab } \\
{[33,39]}\end{array}$ & $\begin{array}{l}2 \text { (but reporting } \\
\text { from same cohort) }\end{array}$ & Moderate = 2 & $\begin{array}{l}\text { Post marketing } \\
\text { surveillance }\end{array}$ & Colorectal cancer & 3085 & $\begin{array}{l}\text { Expert case } \\
\text { review }\end{array}$ & $1.3 \%$ & $51.3 \%$ \\
\hline Cetuximab [38] & 1 & Moderate $=3$ & $\begin{array}{l}\text { Post marketing } \\
\text { surveillance }\end{array}$ & Colorectal cancer & 2006 & $\begin{array}{l}\text { Physician } \\
\text { reported }\end{array}$ & $1.2 \%$ & $41.6 \%$ \\
\hline \multicolumn{9}{|c|}{ Mechanistic target of rapamycin protein (MTOR) inhibitors } \\
\hline $\begin{array}{l}\text { Everolimus [40- } \\
43,45,46,48,49]\end{array}$ & 8 & $\begin{array}{l}\text { Moderate }=3 \\
\text { Low }=3 \\
\text { Very low }=2\end{array}$ & $\begin{array}{c}\text { Meta-analysis }=1 \\
\text { Clinical trial }=2 \text { (same } \\
\text { trial } 2 \text { separate published } \\
\text { analyses) } \\
\text { Observational }=5\end{array}$ & $\begin{array}{l}\text { Neuroendocrine cancer } \\
\text { Renal cell cancer } \\
\text { Renal transplant }\end{array}$ & $40-2261$ & $\begin{array}{l}\text { Variable, } \\
\text { including } \\
\text { radiographic } \\
\text { signs of DIILD }\end{array}$ & $2.8-58 \%$ & $5.4-20 \%$ \\
\hline $\begin{array}{c}\text { Temsirolimus } \\
{[44,47]}\end{array}$ & 2 & Low $=2$ & $\begin{array}{c}\text { Meta-analysis }=1 \\
\text { Clinical trial }=1 \\
\text { Observational study }=1\end{array}$ & $\begin{array}{l}\text { Neuroendocrine cancer } \\
\text { Endometrial cancer } \\
\text { Renal cell cancer }\end{array}$ & $22-408$ & Variable & $29-36 \%$ & $\mathrm{n} / \mathrm{a}$ \\
\hline Sirolimus [48] & 1 & Very low = 1 & Observational & Renal/pancreas transplant & 115 & $\begin{array}{l}\text { Physician } \\
\text { reported }\end{array}$ & $9.5 \%$ & $0 \%$ \\
\hline \multicolumn{9}{|c|}{ Check point inhibitors (CPI) } \\
\hline All CPIs [51-53] & 3 & $\begin{array}{c}\text { High }=2 \\
\text { Moderate }=1\end{array}$ & $\begin{array}{l}\text { Meta-analysis }=2 \\
\text { Observational }=1\end{array}$ & Non-small cell lung cancer & $1826-3232$ & variable & $1.1-3.6 \%$ & $8-9.4 \%$ \\
\hline
\end{tabular}


Table 2. Cont

\begin{tabular}{|c|c|c|c|c|c|c|c|c|}
\hline Drug/Class & Number of Studies & Quality & Study Design & Patient Population & $\begin{array}{l}\text { Sample Size } \\
\text { (Range) }\end{array}$ & $\begin{array}{l}\text { Case Definition } \\
\text { of DIILD }\end{array}$ & $\begin{array}{l}\text { Estimated } \\
\text { Incidence } \\
\text { (Range) }\end{array}$ & $\begin{array}{c}\text { Estimated } \\
\text { Mortality in } \\
\text { Those with } \\
\text { DIILD (Range) }\end{array}$ \\
\hline Ipilimumab [91] & & Low $=1$ & Observational $=1$ & Melanoma & 146 & $\begin{array}{l}\text { Radiographic } \\
\text { evidence of } \\
\text { DIILD }\end{array}$ & $5.44 \%$ & $\mathrm{n} / \mathrm{a}$ \\
\hline Nivolumab [92] & 1 & Low $=1$ & $\begin{array}{l}\text { Post hoc pooled clinical } \\
\text { trial analysis }=1\end{array}$ & Cancer (various types) & 170 & $\begin{array}{c}\text { Physician } \\
\text { reported events }\end{array}$ & $11.7 \%$ & $0 \%$ \\
\hline \multicolumn{9}{|c|}{ Other agents identified } \\
\hline Irinotecan [93] & 1 & Low $=1$ & $\begin{array}{l}\text { Post marketing } \\
\text { surveillance }\end{array}$ & Cancer (various types) & 8864 & $\begin{array}{l}\text { Physician } \\
\text { reported }\end{array}$ & $0.74 \%$ & $24 \%$ \\
\hline $\begin{array}{l}\text { Rituximab } \\
{[67,72-74]}\end{array}$ & 4 & Very low = 4 & $\begin{array}{c}\text { Systematic reviews }=3 \\
\text { Case series }=1\end{array}$ & $\begin{array}{l}\text { Predominantly cancer but } \\
\text { other indications included }\end{array}$ & $16-52$ & Variable & $\mathrm{n} / \mathrm{a}$ & $\mathrm{n} / \mathrm{a}$ \\
\hline Imatinib [94] & 1 & Low $=1$ & $\begin{array}{l}\text { Post marketing } \\
\text { surveillance }\end{array}$ & Leukaemia & 6 & $\begin{array}{l}\text { Physician } \\
\text { reported }\end{array}$ & $\mathrm{n} / \mathrm{a}$ & $6 / 6$ resolved \\
\hline Pemetrexed [95] & 1 & Moderate $=1$ & $\begin{array}{l}\text { Post marketing } \\
\text { surveillance }\end{array}$ & $\begin{array}{c}\text { Mesothelioma } \\
\text { Non-small cell lung cancer }\end{array}$ & 903 & $\begin{array}{l}\text { Expert } \\
\text { committee } \\
\text { review }\end{array}$ & $1.8 \%$ & \\
\hline $\begin{array}{l}\text { Granulocyte } \\
\text { colony } \\
\text { stimulating } \\
\text { factor [96] }\end{array}$ & 1 & Low $=1$ & Observational & $\begin{array}{l}\text { In conjunction with } \\
\text { chemotherapy }\end{array}$ & $\begin{array}{l}40 \text { treated vs. } 25 \\
\text { with } \\
\text { chemotherapy } \\
\text { along }\end{array}$ & $\begin{array}{l}\text { Physician } \\
\text { reported }\end{array}$ & $\begin{array}{l}0.2 \% \text { vs. } 0 \% \text { in } \\
\text { the control } \\
\text { group }\end{array}$ & $\mathrm{n} / \mathrm{a}$ \\
\hline \multicolumn{9}{|c|}{ Rheumatology drugs } \\
\hline $\begin{array}{c}\text { Methotrexate } \\
{[55-61,67]}\end{array}$ & 8 & $\begin{array}{l}\text { Moderate }=3 \\
\text { Low }=4 \\
\text { Very low }=1\end{array}$ & $\begin{array}{c}\text { Meta-analysis }=2 \\
\text { Clinical trial }=3 \\
\text { Observational }=2 \\
\text { Case series }=1\end{array}$ & $\begin{array}{l}\text { Rheumatoid arthritis } \\
\text { Psoriasis, psoriatic arthritis or } \\
\text { inflammatory bowel } \\
\text { Primary biliary cirrhosis }\end{array}$ & 29-3188 & variable & $0.06-15 \%$ & $10-33 \%$ \\
\hline $\begin{array}{c}\text { Tumour } \\
\text { necrosis factor } \\
\text { inhibitors } \\
{[67-72,97,98]}\end{array}$ & 8 & $\begin{array}{l}\text { Moderate }=4 \\
\text { Low }=1 \\
\text { Very low }=3\end{array}$ & $\begin{array}{c}\text { Post marketing } \\
\text { surveillance }=3 \text { (2 papers } \\
\text { report on } 1 \text { study) } \\
\text { Observational study }=3 \\
\text { Systematic review of case } \\
\text { reports }=3\end{array}$ & $\begin{array}{l}\text { Predominantly rheumatoid } \\
\text { arthritis but cases in other } \\
\text { diseases }\end{array}$ & $233-13,894$ & variable & $0.6 \%$ & $32 \%$ \\
\hline $\begin{array}{l}\text { Leflunomide } \\
\text { [62-66] }\end{array}$ & 5 & $\begin{array}{l}\text { Moderate }=1 \\
\text { Low }=3 \\
\text { Very low }=1\end{array}$ & $\begin{array}{c}\text { Meta-analysis of RCTs = } 1 \\
\text { Case control via claims } \\
\text { database }=1 \\
\text { Post marketing } \\
\text { surveillance }=2 \\
\text { Case series }=1\end{array}$ & Rheumatoid arthritis & $2274-62,734$ & variable & $0-1.2 \%$ & $19-41 \%$ \\
\hline
\end{tabular}


Table 2. Cont

\begin{tabular}{|c|c|c|c|c|c|c|c|c|}
\hline Drug/Class & Number of Studies & Quality & Study Design & Patient Population & $\begin{array}{l}\text { Sample Size } \\
\text { (Range) }\end{array}$ & $\begin{array}{l}\text { Case Definition } \\
\text { of DIILD }\end{array}$ & $\begin{array}{c}\text { Estimated } \\
\text { Incidence } \\
\text { (Range) }\end{array}$ & $\begin{array}{c}\text { Estimated } \\
\text { Mortality in } \\
\text { Those with } \\
\text { DIILD (Range) }\end{array}$ \\
\hline \multicolumn{9}{|c|}{ Cardiology drugs } \\
\hline $\begin{array}{c}\text { Amiodarone } \\
{[80-88,99-101]}\end{array}$ & 12 & $\begin{array}{l}\text { Moderate }=2 \\
\text { Low }=5 \\
\text { Very low }=5\end{array}$ & $\begin{array}{l}\text { Observational }=7 \\
\text { Case series }=5\end{array}$ & Cardiovascular disease & $13-500$ & $\begin{array}{c}\text { Variable, often } \\
\text { not restricted to } \\
\text { DIILD }\end{array}$ & $1.2-8.8 \%$ & $0-41 \%$ \\
\hline Bepridil [102] & 1 & Low $=1$ & Observational & Cardiovascular disease & 222 & $\begin{array}{l}\text { Standardised } \\
\text { definition }\end{array}$ & $6.3 \%$ & $0 \%$ \\
\hline Statins [103] & 1 & Very low $=1$ & $\begin{array}{c}\text { Observational (Adverse } \\
\text { events reporting } \\
\text { database) }\end{array}$ & $\begin{array}{l}\text { Cardiovascular } \\
\text { disease/prevention }\end{array}$ & & & $\begin{array}{l}1 / 40 \text { adverse } \\
\text { event reports for } \\
\text { statins were ILD }\end{array}$ & $\mathrm{n} / \mathrm{a}$ \\
\hline \multicolumn{9}{|c|}{ Anti-infection agents } \\
\hline $\begin{array}{l}\text { Nitrofurantoin } \\
{[75-78,104]}\end{array}$ & 5 & $\begin{array}{c}\text { Low }=3 \\
\text { Very low }=2\end{array}$ & $\begin{array}{c}\text { Case-control study = } 1 \\
\text { Registry study }=1 \\
\text { Post marketing } \\
\text { surveillance }=1 \\
\text { Case series }=2\end{array}$ & $\begin{array}{l}\text { Chronic and acute treatment of } \\
\text { urinary tract infection }\end{array}$ & $10-70,804$ & $\begin{array}{l}\text { Variable, some } \\
\text { used "any ILD" } \\
\text { after use of drug }\end{array}$ & $3.65 \%$ & $1.34 \%$ \\
\hline $\begin{array}{c}\text { Daptomycin } \\
{[79,105]}\end{array}$ & 2 & Low $=2$ & $\begin{array}{l}\text { Observational study = } 1 \\
\text { Post marketing } \\
\text { surveillance = } 1\end{array}$ & $\begin{array}{c}\text { Infection (one study } \\
\text { specifically infective } \\
\text { endocarditis) }\end{array}$ & $58-102$ & Variable & $2.9 \%$ & $\mathrm{n} / \mathrm{a}$ \\
\hline Interferon [106] & 1 & Very low $=1$ & $\begin{array}{l}\text { Systematic review of case } \\
\text { reports }\end{array}$ & Hepatitis C & 25 & Variable & $\mathrm{n} / \mathrm{a}$ & $\mathrm{n} / \mathrm{a}$ \\
\hline
\end{tabular}




\subsection{Risk Factors for the Development of DIILD}

Risk factors for the development of DIILD vary according to the disease, drug and population being treated. Certain risk factors have featured prominently across drugs.

Age: Increased age has been identified as a significant risk factor for DIILD for treatment with bleomycin, gemcitabine, EGFR-targeted agents, leflunomide, MTX, amiodarone and nitrofurantoin [23, $30,33,58,62,76,77,85,95,104,107]$. For bleomycin, dose reductions are recommended together with weekly chest radiographs and close follow-up after completion of therapy to monitor for DIILD in patients $>60$ years old. In contrast, no age association has been found with MTOR inhibitors [42,52,62].

Pre-existing lung disease: Pre-existing ILD or Idiopathic Pumonary Fibrosis (IPF) is an independent risk factor for DIILD with a wide range of agents $[13,34,45,67,89,91,95,108,109]$. For example, in NSCLC patients, prior ILD was associated with a 3.19-fold increased risk of DIILD in Japan [34]. Increased DIILD risk has also been associated with pre-existing Chronic Obstructive Pulmonary Disease (COPD), bronchiectasis and asbestosis [34,95,109,110].

Smoking: Smokers are at increased risk of DIILD when treated with gemcitabine, EGFR-targeted agents and methotrexate [20,33,56,58,95,108-112].

Drug dose: A clear dose-dependent relationship is well recognised for bleomycin, amiodarone and nitrofurantoin and is described in the Common Causative Drugs section. However, findings are not consistent for other agents across studies [41,45].

Underlying disease characteristics: In oncology, poor performance status and advanced or metastatic stages of disease are independent risk factors for DIILD [30,33,107,110]. One Japanese post-marketing study observed a 3-fold higher risk of DIILD for patients with NSCLC treated with gemcitabine compared to other cancers treated with gemcitabine [30]. Whilst there may be confounding due to a higher incidence of pre-existing ILD in NSCLC, this difference was not observed in studies of other agents used for this indication [46,95]. In RA, methotrexate DIILD risk was increased in patients with high inflammatory markers, low albumin, extra-articular disease and high levels of disability $[67,111]$.

Sex: Male sex has been reported as a risk factor for DIILD in some studies following treatment with EFGR inhibitors, pemetrexed, methotrexate and amiodarone [33,58,85,95].

Other therapies: For gemcitabine, prior chemotherapy carried a relative risk of DIILD of 1.45 [30, 33]. Conversely, two studies (one in erlotinib-treated and one in immune checkpoint inhibitor-treated patients) found that re-treatment with the same drug or another drug in the same class actually carried a lower DIILD risk [34,52]. Prior thoracic radiotherapy also increased DIILD risk in lung cancer patients [34]. In RA, prior MTX exposure increased the risk of leflunomide-induced ILD [65], and prior DMARD therapy was independently associated with a higher risk of MTX-induced DIILD [58]. However, such studies may be confounded by such patients having more severe or progressive disease.

Other risk factors: Other potential risk factors for DIILD include genetic susceptibility, higher alcohol consumption, renal dysfunction and diabetes [26,34,58]. Certain (Cytochrome P450) CYP enzyme polymorphisms increase the risk for drugs metabolised by CYP enzymes, and certain (human leukocyte antigen) HLA allelic variants have been linked with DIILD following erlotinib-gemcitabine combination therapy $[113,114]$. Weiner et al. reported that patients switching to sirolimus at a later stage of anti-rejection treatment were at higher risk of DIILD, as were patients with impaired renal function [115]. Higher rates were also observed in Japanese patients, and this may be a combination of genetic susceptibility and variation in reporting, which has been observed between different countries [5].

\subsection{Radiological Investigation of DIILD and Prevalent Radiopathological Patterns}

Unilateral or, more commonly, bilateral pulmonary infiltrates on a chest radiograph may be the first indication of DIILD [116]; however, $25-75 \%$ of chest radiographs are normal in cases of clinically suspected DIILD $[89,116,117]$. 
CT has higher sensitivity for detecting ILD features and is the imaging modality of choice $[45,118]$. The main limitations are exposure to ionising radiation, an issue minimised with modern scanners and the use of iterative reconstruction. To date, $\mathrm{CT}$ assessments have been non-specific for DIILD, as the numerous patterns of interstitial change are commonly seen in other ILDs.

Formal studies assessing CT in DIILD are limited by inconsistent terminology, many having been conducted prior to the current ATS/ERS ILD classification [1]. Pathological terms such as chronic interstitial pneumonia (CIP) are common in older imaging studies [14-16], but they have limited utility due to relatively poor agreement between radiological and pathological findings $[15,119]$. Several studies have compared histopathological and imaging findings in DIILD [12,15,16,73,119, 120]. A prospective study of 42 patients with DIILD undergoing transbronchial lung biopsy (TBLB) or bronchoalveolar lavage (BAL) reported an overall diagnostic agreement of $67 \%$ [15], while a retrospective analysis of patients with DIILD undergoing TBLB $(n=4)$ or open biopsy $(n=16)$ at a single centre reported a lower diagnostic agreement (45\%) [119]. In contrast, CT features of diffuse alveolar damage (DAD) are highly congruous with histopathological features of DAD [1] and confer high mortality $[33,39,80,90,94,95,121,122]$. In general, the correlation imaging pattern of CT and pathology is suboptimal [119].

DIILD most commonly manifests as ground glass opacification (GGO) with or without consolidation $[16,17,44,80]$ and has a basal, peripheral and bilateral distribution, often affecting multiple lobes $[43,91,92]$. Heterogeneity in reporting makes the true incidence of each pattern difficult to establish. Changes resembling organising pneumonia (OP) are most commonly reported, followed by non-specific interstitial pneumonia (NSIP) and hypersensitivity pneumonitis (HP)-like changes [12-15,33,34,39,43,73,90-94,122]. NSIP is reportedly more common in hospitalised patients [12] and in chemotherapy-induced DIILD [12,13]. Reticular changes and volume loss (termed CIP in older studies) occur less commonly [73]. In the modern classification, this is most closely aligned with fibrotic NSIP or usual interstitial pneumonia (UIP) [1]. In some cases, hilar lymphadenopathy and pleural effusions were found, often when associated with eosinophilia [123]. Appearances consistent with sarcoidosis have been reported in at least six cases following treatment with interferon-alpha [15]. Another pattern of ground glass opacities with interlobular septal thickening, termed "crazy paving", is recognised in DIILD, but is neither sensitive (present in $12 \%$ of DIILD) nor specific, as it is common in the context of heart failure [123].

Qualitative CT features are not specific to DIILD, as other causes of these radiological patterns, such as atypical infections (particularly in immunosuppressed patients) or connective tissue disease-associated ILD, may confound interpretation [44,45]. In addition, the radiological patterns of DIILD for the same drug are highly variable (e.g., NSIP, DAD and COP patterns are seen in amiodarone-induced ILD [30]) and, conversely, the same pattern can be a feature of numerous drugs (e.g., OP-like pattern is seen in a number of agents, including EGFR RTKIs, checkpoint inhibitors and amiodarone $[39,51,84])$.

\subsection{Non-Imaging Diagnostic Investigations}

\subsubsection{Pulmonary Physiology}

Pulmonary physiology is important in the assessment of suspected DIILD but, like CT, lacks specificity. Reduction in $\mathrm{D}_{\mathrm{LCO}}$ is a presymptomatic feature of DIILD, and changes in FVC correlate with clinical progression in bleomycin-treated patients [18,124]. The sensitivity of pulmonary function tests (PFTs) varies within studies. One historic study in suspected bleomycin lung reported abnormal PFTs in only 31/150 patients [18]. Yamada et al. evaluated the diagnostic accuracy of percentage change in $\mathrm{D}_{\mathrm{LCO}}$ in patients treated with amiodarone [85]. Sensitivities of $76 \%, 68 \%$ and $59 \%$ were found for a $10 \%, 15 \%$ and $20 \%$ reduction in $\mathrm{D}_{\mathrm{LCO}}$, respectively. In a study of nitrofurantoin-induced DIILD, all patients had impaired DLCO but only 2/17 had abnormal FVC [77]. 


\subsubsection{Bronchoalveolar Lavage (BAL)}

BAL findings, including raised lymphocyte, neutrophil and eosinophil counts [122,125-127], are not specific for DIILD, as they also occur in types of inflammatory or infective lung disease [126]. Reversal of the CD4:CD8 lymphocyte ratio has been reported in some, but not all, studies, but again is not specific for DIILD [127-130]. Other reported findings include cellular abnormalities, such as nuclear enlargement and hyperchromasia, lipid inclusions and haemosiderin-laden macrophages $[15,131]$. The presence of reactive type II pneumocytes has also been described in severe cases of DIILD [16].

Opportunistic infection is high on the differential diagnosis of most DIILD. In some studies, positive BAL microbiology led to a revised diagnosis in suspected DIILD cases [41,111,116,132]. In a study of 26 everolimus-treated patients initially diagnosed with DIILD, $12(46 \%)$ were subsequently diagnosed with Pneumocystis jiroveci [41]. Currently, the key role of BAL is to aid in the exclusion of other causes, especially infection.

\subsubsection{Lung Biopsy}

The role of lung biopsy has been limited to small studies, and almost all histopathological patterns have been reported in DIILD; however, none are specific for DIILD [15,16]. There is, therefore, limited evidence for the routine use of biopsy in the diagnosis of DIILD but, like BAL, it may be useful in selected cases where there is diagnostic uncertainty or to exclude other causes.

\subsubsection{Circulating Biomarkers}

Krebs von den Lungen-6 (KL-6) is a mucin-like glycoprotein secreted by type II alveolar pneumocytes and bronchial epithelial cells in response to damage and regeneration in the context of ILD. In a prospective study, increased KL-6 was observed in 53\% of DIILD patients and correlated with the DAD pattern and more extensive lung involvement [14]. Changes in KL-6 over time corresponded with the clinical course. A second study reported a predictive association between the ratio of KL-6 to sialyl SSEA-1 (SLX) and subsequent DIILD in lung cancer patients undergoing chemotherapy [90]. The specificity of KL-6 in DIILD has not, however, been established. Other biomarkers, including peripheral eosinophilia and raised inflammatory markers, are non-specific and not diagnostic for DIILD.

\subsection{The Role of Glucocorticoids (GCs) in the Treatment of DIILD}

Our review was limited by a lack of randomised data, missing data on dose and duration, and variation in criteria for patient selection and dose. Assessing the impact of GC therapy on resolution of DIILD or survival was also hampered by the common practice of introducing steroids contemporaneously with the withdrawal of the offending drug. Table 3 summarises studies where either dosing information and/or outcomes from GC treatment were available.

\subsubsection{Efficacy}

The reported efficacy of GC treatment in DIILD varied widely. In a series of 75 cancer patients with irinotecan-induced DIILD treated with GC, 46 (61\%) recovered and $22(29 \%)$ died [93]. In 10 pemetrexed DIILD patients treated with GC, five patients $(50 \%)$ responded, four $(40 \%)$ failed to respond and one died [95]. Rebattu et al. also reported 100\% recovery after drug discontinuation and GC therapy in six DIILD cases associated with combination gemcitabine and docetaxel therapy [133]. In one series of all-cause DIILD, 62\% (29/47 patients) received GCs and the remaining 18 patients recovered without supportive GC therapy [12]. The retrospective nature of these studies and the lack of specific criteria for the use of GC means there is a high risk of channelling bias, i.e., GCs tend to be used more commonly in those with severe disease and a DAD pattern. 


\subsubsection{GC Dose and Duration}

GC doses ranged widely and included high-dose oral and IV methylprednisolone regimes, with dosing and duration in part guided by the radiological pattern $[59,134]$. Takatani et al. reported a median cumulative dose of $5240 \mathrm{mg}$ prednisolone for DAD, compared to $2722 \mathrm{mg}$ for OP, $415 \mathrm{mg}$ for HP and $264 \mathrm{mg}$ for NSIP groups [122]. Weak supportive evidence for the role of GCs is suggested by an increased risk of DIILD relapse when GCs are stopped or tapered early (within 3 months of onset) $[80,116]$. The merit of high dosages is not established.

\subsubsection{DIILD Subsets and GC Responses}

The DAD pattern has the poorest prognosis, and, in one series, no DAD patients improved with GC treatment, and the overall mortality was 37.5\% [12]. Reported improvements with GC therapy for other radiological patterns were: $75 \%$ (3/4 patients) for OP, $45.8 \%$ (11/24 patients) for NSIP and $36.4 \%$ for HP pattern [12].

Although GC therapy was used in many studies, there is currently no evidence on which to base recommendations for GC use in DIILD. The use of GC in therapy is recommended in severely affected patients, with dosing regimens at the discretion of the attending physician. Further studies are required in order to develop more detailed treatment recommendations.

\subsection{Prognosis}

DIILD prognosis varies between drugs and different studies. Complete recovery is possible following dose reduction, drug withdrawal and/or concomitant GC use [17,34,45,73,91,110]. Nevertheless, a significant proportion fails to improve, or follows a progressive clinical course [29, $34,91,110]$. DIILD mortality is often due to respiratory failure, multiorgan failure, progression of the primary underlying disease or as an adverse effect of GC therapy (e.g., infection) $[80,106]$. In the context of oncology, mortality ranges from 14 to $51.3 \%$ [13,22,30,33,34,40,93,109], whilst in non-cancer settings, mortality ranges from 0 to $41 \%[26,59-61,63,64,71,106]$.

\section{Factors Predicting Mortality}

Clinical characteristics: Acute and severe presentations are the most consistent predictors of mortality. In particular, a requirement for mechanical ventilation is associated with mortality rates of $>60 \%[135,136]$. Rapid symptom onset, higher initial disease severity and hypoxaemia at presentation also predict mortality $[63,64,80]$. Pre-existing ILD, male sex, age $>65$ years and a diagnosis of NSCLC are also associated with higher case fatality rates [93]. In NSCLC patients, a poor performance status $(2-4), \geq 2$ prior chemotherapy regimens and $<50 \%$ remaining normal lung area also predict DIILD mortality [34,108].

Radiological patterns: For CT, a greater extent of lung injury and a homogenous pattern are associated with higher mortality in amiodarone-treated patients [106]. DAD and NSIP patterns also predict poorer outcomes [80,119] (with the DAD pattern, 40-83.3\% mortality) [33,34,95]. Honeycombing with interstitial pneumonia is also associated with higher mortality [34]. Of note, however, is that full recovery has been seen with diffuse ground glass opacities [95], and some studies have not found CT patterns to be prognostic $[119,135]$.

Other: For BAL, the presence of desquamated type II pneumocytes is associated with mortality [16]. Others have also found that circulating and/or BAL KL-6 and heat shock protein 47 are associated with higher mortality $[12,119,121,122]$. Their association with a more severe clinical presentation and with $\mathrm{DAD}$, however, means that their incremental value as prognostic markers remains unclear. 
Table 3. Summary of studies which included information on use of glucocorticoids.

\begin{tabular}{|c|c|c|c|c|c|}
\hline Author & Drug & $\begin{array}{c}\text { Patient } \\
\text { Population }\end{array}$ & Sample Size & Glucocorticoids Dose (Oral or IV) & Response \\
\hline $\begin{array}{l}\text { Mankikian et al. } \\
{[80]}\end{array}$ & Amiodarone & DIILD & 46 & $\begin{array}{l}\text { Median dose of } 1 \mathrm{mg} / \mathrm{kg} \\
15 \text { surviving patients followed and } 9(60 \%) \\
\text { received glucocorticoids for } 3-29 \text { months. } \\
\text { All surviving patients successfully had } \\
\text { glucocorticoids withdrawn }\end{array}$ & $\begin{array}{l}76 \% \text { got glucocorticoids but no obvious difference in } \\
\text { survival outcomes. Three patients treated for }<3 \\
\text { months relapsed and glucocorticoids restarted. No } \\
\text { relapse in patients treated for }>6 \text { months }\end{array}$ \\
\hline $\begin{array}{l}\text { Kakugawa et al. } \\
\text { [12] }\end{array}$ & Various & DIILD & 47 & $\begin{array}{l}29 \text { of } 47 \text { patients received glucocorticoid therapy. } \\
\text { Decision on glucocorticoid therapy was } \\
\text { physician-based rather than protocol-based. } \\
\text { No dosing information available }\end{array}$ & $\begin{array}{l}\text { None of the patients with a DAD pattern on HRCT } \\
\text { improved with glucocorticoid treatment, and DAD } \\
\text { group had a } 37.5 \% \text { mortality. } 75 \% \text { of those with OP } \\
\text { pattern on HRCT ( } 3 \text { of } 4 \text { ) improved with } \\
\text { glucocorticoid treatment. With an NSIP pattern, } 45.8 \% \\
\text { (11 of } 24 \text { patients) improved with glucocorticoid } \\
\text { treatment. Hypersensitivity pneumonitis (HP) pattern } \\
\text { was associated with a } 36.4 \% \text { response to } \\
\text { glucocorticoid therapy. }\end{array}$ \\
\hline Ki et al. [134] & $\begin{array}{l}\text { Bleomycin with } \\
\text { cisplatin and } \\
\text { vincristine }\end{array}$ & $\begin{array}{l}\text { Cervical cancer } \\
\text { patients treated } \\
\text { with prior } \\
\text { mentioned } \\
\text { agents [59] }\end{array}$ & $\begin{array}{l}61 \text { ( } 7 \text { cases of } \\
\text { DIILD) }\end{array}$ & $\begin{array}{l}4 \text { with bleomycin injury received glucocorticoid } \\
\text { Different regimens within the study. } \\
1 \text { patient who improved received } 40 \mathrm{mg} / \text { day } \\
\text { methylprednisolone, followed by } 10 \mathrm{mg} \text { daily. } \\
2 \text { acutely ill patients received IV } \\
\text { methylprednisolone } 500 \mathrm{mg} / \text { day } \times 3 \text { days. } \\
1 \text { patient received } 1 \mathrm{mg} / \mathrm{kg} / \text { day prednisolone, } \\
\text { then } 0.5 \mathrm{mg} / \mathrm{kg}\end{array}$ & $\begin{array}{l}\text { Of these } 4 \text { patients, } 2 \text { died, } 1 \text { improved, } 1 \\
\text { non-responder. } \\
\text { Insulin-dependent diabetes developed in } 2 \text { patients }\end{array}$ \\
\hline Kim et al. [105] & Daptomycin & Suspected DIILD & $\begin{array}{l}58 \text { ( } 7 \text { definite } \\
\text { DIILD cases, } 13 \\
\text { probable cases })\end{array}$ & $\begin{array}{l}\text { No dosing information } \\
\text { Definite cases: } 5 \text { of } 7 \text { received glucocorticoid (1 } \\
\text { intravenous) } \\
\text { Probable cases: } 9 \text { of } 13 \text { received glucocorticoid }\end{array}$ & $\begin{array}{l}\text { No deaths } \\
1 \text { required long-term treatment }\end{array}$ \\
\hline Rebattu et al. [133] & $\begin{array}{l}\text { Gemcitabine with } \\
\text { docetaxel }\end{array}$ & $\begin{array}{l}\text { NSCLC patients } \\
\text { treated with } \\
\text { prior mentioned } \\
\text { agents }\end{array}$ & $\begin{array}{l}49 \text { (6 DIILD } \\
\text { cases) }\end{array}$ & $6 / 6$ received glucocorticoids & All recovered \\
\hline Ohnishi et al. [94] & Imatinib & DIILD & 27 & $\begin{array}{l}19 / 27 \text { received high dose glucocorticoids } \\
5 / 27 \text { moderate dose glucocorticoids } 3 / 27 \text { no } \\
\text { treatment }\end{array}$ & $\begin{array}{l}7 / 27 \text { resolved } \\
16 / 27 \text { improved } \\
4 / 27 \text { no improvement }\end{array}$ \\
\hline Sharma et al. [59] & Methotrexate & $\begin{array}{l}\text { Primary biliary } \\
\text { cirrhosis patients } \\
\text { treated with } \\
\text { methotrexate }\end{array}$ & $\begin{array}{l}43 \text { (6 DIILD } \\
\text { cases) }\end{array}$ & $\begin{array}{l}5 / 6 \text { received prednisolone } 60 \mathrm{mg} \text { IV daily } \\
\text { Duration of intravenous route and } \\
\text { glucocorticoids taper unclear }\end{array}$ & $\begin{array}{l}4 / 5 \text { given glucocorticoids responded, } \\
1 \text { patient died from liver decompensation }\end{array}$ \\
\hline
\end{tabular}


Table 3. Cont

\begin{tabular}{|c|c|c|c|c|c|}
\hline Author & Drug & $\begin{array}{c}\text { Patient } \\
\text { Population }\end{array}$ & Sample Size & Glucocorticoids Dose (Oral or IV) & Response \\
\hline White et al. [45] & Everolimus & $\begin{array}{l}\text { Advanced renal } \\
\text { cell cancer } \\
\text { patients treated } \\
\text { with everolimus }\end{array}$ & $\begin{array}{l}416 \text { ( } 37 \text { DIILD } \\
\text { cases) }\end{array}$ & $\begin{array}{l}16 / 37 \text { patients received glucocorticoids } \\
\text { All } 10 \text { patients with grade } 3 \text { pneumonitis } \\
\text { received glucocorticoids }\end{array}$ & $\begin{array}{l}10 \text { patients with grade } 3 \text { pneumonitis who received } \\
\text { glucocorticoids } \\
3 / 10 \text { continued everolimus: } 1 \text { died and } 2 \text { recovered } \\
7 / 10 \text { discontinued: } 5 \text { recovered, } 1 \text { had ongoing } \\
\text { disease, } 1 \text { died }\end{array}$ \\
\hline Tomii et al. [95] & Pemetrexed & $\begin{array}{l}\text { Mesothelioma } \\
\text { and NSCLC } \\
\text { DIILD patients }\end{array}$ & $\begin{array}{l}1586 \text { ( } 10 \text { DIILD } \\
\text { cases) }\end{array}$ & 10 cases, all of which received glucocorticoids & $\begin{array}{l}5 / 10 \text { patients deemed glucocorticoids responsive, } 1 \\
\text { indeterminate, } 4 \text { non-glucocorticoids responders died }\end{array}$ \\
\hline Osawa et al. [33] & Panitumumab & $\begin{array}{l}\text { Colorectal cancer } \\
\text { patients treated } \\
\text { with } \\
\text { panitumumab }\end{array}$ & $\begin{array}{l}3085 \text { ( } 39 \text { DIILD } \\
\text { cases) }\end{array}$ & No dosing information available & $\begin{array}{l}\text { Minimal information on glucocorticoid impact other } \\
\text { than statement that most of the } 20 \text { patients who died } \\
\text { had received glucocorticoids }\end{array}$ \\
\hline Yoshii et al. [93] & Irinotecan & $\begin{array}{l}\text { Cancer patients } \\
\text { treated with } \\
\text { irinotecan }\end{array}$ & $\begin{array}{l}8864 \text { (153 DIILD } \\
\text { cases, } 83 \text { with } \\
\text { clinical } \\
\text { information) }\end{array}$ & $\begin{array}{l}75 / 83 \text { patients received glucocorticoids } \\
\text { No dosing information available }\end{array}$ & $\begin{array}{l}46 / 75 \text { of those treated recovered or improved, } 5 / 75 \\
\text { no response, } 22 / 75 \text { died, } 2 / 75 \text { unknown outcome } \\
\text { DAD pattern associated with lack of response to } \\
\text { glucocorticoids }\end{array}$ \\
\hline Liote et al. [73] & Rituximab & DIILD & 45 & $\begin{array}{l}27 / 45 \text { cases of rituximab DIILD received } \\
\text { glucocorticoid. Dosing unclear. } \\
\text { Some patients received } 1 \mathrm{mg} / \mathrm{kg} \text { of body weight } \\
\text { concomitantly with re-challenge. }\end{array}$ & $\begin{array}{l}\text { No recurrence of rituximab injury in } 3 \text { patients } \\
\text { receiving re-challenge with rituximab and } \\
\text { concomitant } 1 \mathrm{mg} / \mathrm{kg} \text { methylprednisolone } \\
\text { Early onset acute presentation: } 5 \text { patients all received } \\
\text { glucocorticoids, } 2 \text { died } \\
\text { Late onset chronic presentation in } 3 \text { patients who } \\
\text { recovered with glucocorticoid therapy } \\
\text { Authors recommend longer period of glucocorticoids } \\
\text { usage rather than just boluses at each rituximab } \\
\text { infusion, and a gradual taper to avoid rebound }\end{array}$ \\
\hline $\begin{array}{l}\text { Takatani et al. } \\
\text { [122] }\end{array}$ & Various & DIILD & & $\begin{array}{l}\text { DAD group received median cumulative } \\
\text { glucocorticoids dose of } 5240 \mathrm{mg} \text {, range } \\
1000-9195 \mathrm{mg} \text {; NSIP group median of } 264 \text {, range } \\
0-735 \mathrm{mg} \text {; HP group median } 415 \text {, range } 0-4470 \\
\text { mg; OP group median 2722, range 0-7835 mg }\end{array}$ & $\begin{array}{l}\text { Days of oxygen therapy correlated well with } \\
\text { cumulative doses of glucocorticoid therapy, i.e., the } \\
\text { sicker patients received more glucocorticoids. OP } \\
\text { pattern patients showed full recovery with } \\
\text { glucocorticoids. No deaths in this group of } 34 \\
\text { non-chemotherapy DIILD pts. } 11 \text { pts recovered fully } \\
\text { without glucocorticoids }\end{array}$ \\
\hline
\end{tabular}




\begin{tabular}{|c|c|c|c|c|c|}
\hline Author & Drug & $\begin{array}{c}\text { Patient } \\
\text { Population }\end{array}$ & Sample Size & Glucocorticoids Dose (Oral or IV) & Response \\
\hline Chap et al. [116] & $\begin{array}{l}\text { Cyclophosphamide, } \\
\text { cisplatin and } \\
\text { BCNU }\end{array}$ & $\begin{array}{l}\text { Breast cancer } \\
\text { patients treated } \\
\text { with prior } \\
\text { mentioned }\end{array}$ & $\begin{array}{l}64 \text { ( } 37 \text { cases of } \\
\text { DIILD) }\end{array}$ & $\begin{array}{l}37 / 37 \text { treated with prednisolone } 60 \mathrm{mg} \text { oral } \\
\text { twice daily } \times 10 \text { days, then } 30 \mathrm{mg} / \text { day } \times 1 \\
\text { week, } 20 \mathrm{mg} / \text { day } \times 1 \text { week, } 15 \mathrm{mg} / \text { day } \times 1 \\
\text { week, followed by } 5 \mathrm{mg} \text { taper on daily dose each } \\
\text { week. } \\
\text { Initiation of prednisolone based on scoring } \\
\text { system; crackles on lung auscultation }=2 \text {, drop } \\
\text { in } \mathrm{D}_{\mathrm{LCO}} \text { by }>10 \% \text { from baseline }=3 \text {, drop in } \mathrm{O}_{2} \\
\text { saturation } \geq 4 \% \text { with } 2 \text { min walk }=3 \text {, interstitial } \\
\text { infiltrates on } C X R=3 \text {. Patients with a score } \geq 6 \\
\text { received prednisolone as above. }\end{array}$ & $\begin{array}{l}\text { Glucocorticoid therapy associated with rapid clinical } \\
\text { improvement in "most patients" (absolute numbers } \\
\text { not available). } 11 \text { patients required prolonged } \\
\text { prednisolone therapy ( } 4-8 \text { months), having } \\
\text { experienced exacerbation of symptoms when } \\
\text { prednisolone reduced to } 15-20 \mathrm{mg} / \text { day }\end{array}$ \\
\hline Hamada et al. [30] & Gemcitabine & $\begin{array}{l}\text { pancreatic, lung, } \\
\text { urothelial, breast, } \\
\quad \text { ovarian }\end{array}$ & $\begin{array}{l}25,924 \text { (428 cases } \\
\text { of ILD not } \\
\text { verified as } \\
\text { DIILD) }\end{array}$ & $\begin{array}{l}363 / 428(84 \%) \text { patients with ILD received either } \\
\text { oral or intravenous glucocorticoids }\end{array}$ & $\begin{array}{l}20 \% \text { of hospitalised DIILD patients with severe } \\
\text { disease died, no data on glucocorticoid-treated group } \\
\text { outcome versus non-glucocorticoid-treated patients }\end{array}$ \\
\hline
\end{tabular}

Abbreviations: DILD = Drug induced Interstitial Lung Disease; DAD = Diffuse alveolar damage; HRCT = High resolution Computer Tomography; OP = Organising Pneumonia; NSIP = Non specific interstitial pneumonia. And HP = Hypersensitivity pneumonitis 


\section{Discussion}

DIILD may affect a wide spectrum of patients globally, with a significant impact on survival in multiple contexts. Evidence on the true incidence and mortality, case definition, diagnostic tests and optimal treatment of DIILD is lacking. The TRISTAN Consortium has set out to address some of these gaps, and this systematic review provides a baseline assessment of what is already known about this condition and Table 4 highlights the key findings of this PRISMA compliant systematic review.

Few studies have examined the incidence rates in the general population, and the available pharmacovigilance studies likely significantly underestimate the risk. A significant risk of DIILD has been demonstrated with newer agents, such as EGFR-targeted therapies, highlighting the urgent need to investigate the true scale of DIILD and its impact on treatment and mortality in a contemporaneous population.

Whilst we identify a large number of relevant papers in this review, the majority of studies were of low quality, with a high risk of bias. The lack of standardised case definition used across studies made it impossible to pool data and conduct a formal meta-analysis. While a large number of studies reported rates of new ILD occurrence and pulmonary toxicity with specific agents, there was a lack of high-quality studies investigating DIILD in a non-agent-specific setting. Other significant factors limiting our ability to draw firm conclusions included the over-representation of some geographical areas, such as Japan, where rates of ILD and reporting methods may differ from other parts of the world. There was also significant confounding in a number of studies, and limitations in study design and sample size all added to difficulties in data synthesis.

From published data, there are no radiopathological patterns specific to DIILD and there are no investigations which, alone or in combination, can be confidently used to diagnose DIILD. Imaging with CT plays an important role in the identification of lung changes, and bronchoscopy is helpful for excluding infection. All tests, however, lack specificity in DIILD; therefore, the diagnosis largely remains one of exclusion. The lack of specific diagnostic markers for DIILD has an impact on drug development, particularly in cancer and rheumatology populations, which have a high background prevalence of ILD and significant respiratory infection risk. Better biomarkers to detect early safety signals and to distinguish between disease and drug-related ILD are needed. More specific imaging biomarkers derived from quantitative $\mathrm{CT}$ analyses, positron emission tomography or MRI (e.g., hyperpolarised 129Xe MRI, oxygen-enhanced MRI, dynamic contrast-enhanced MRI) better characterise lung structure and function, and may facilitate the development of biomarkers specific to DIILD [137-139].

Evidence for managing DIILD was distinctly lacking. In some studies, agents were continued even with grade 3 DIILD [45]. The risk of development and progression of DIILD must always be balanced against the negative impact of stopping the drug on outcomes/survival, and this delicate balance may vary depending on the condition and treatment efficacy. The literature had no consistent approach to decision making on drug withdrawal and no robust evidence base for the use of GCs. We found a number of possible risk factors for the development of DIILD and prognosis, which could be considered when developing a consensus on the management approach. We have identified points to consider in any approach to GC use in DIILD. However, prospective studies are required, with more detailed recommendations needed to aid decision making on drug initiation, withdrawal and monitoring in high-risk groups.

It is important to note that this review does not provide a comprehensive catalogue of all drugs implicated in the causation of drug-induced lung disease, specifically as we excluded case reports and studies with a sample size of less than 10 . The most recent data from the comprehensive website Pneumotox (www.pneumotox.com) highlight 1406 drugs, substances or procedures reported as having caused pulmonary injury (personal communication Ph Camus through his website, 3 October 2018). Approximately 800 of these agents/procedures had less than 10 reports on the website. While not all of these substances are licensed drugs nor cause an interstitial lung disease pattern of injury, this underlines a limitation of the current review. 
Overall, this systematic review informs the formulation of a research agenda in DIILD, and we propose several key areas for further investigation and development, including:

(i) A standardised case definition for the study of DIILD to be used in clinical trials and observational studies.

(ii) Validation of better biomarkers for detecting early DIILD and discriminating from other causes of ILD.

(iii) An evidence base for the management of DIILD, including through clinical trials to the efficacy and optimal dosing of GCs in DIILD.

The TRISTAN Consortium will address this research agenda and will focus on prospective studies using novel imaging methods and biomarkers, with accompanying pre-clinical studies to interrogate mechanisms and validate imaging methods. Our aim is to develop better biomarkers for use, both in drug development and clinical practice, for the diagnosis and monitoring of DIILD and other ILD subtypes. We also aim to undertake prospective work to estimate the burden of DIILD and take steps towards developing a consensus on management.

Table 4. Key findings for each sub-question.

What is the incidence and prevalence of DIILD?

- Incidence rates estimated between 0.41 and 12.4 per million per annum

- DIILD accounts for 3-5\% of prevalent cases of ILD

What drugs are commonly associated with DIILD?

- Cancer drugs followed by rheumatology drugs, amiodarone and antibiotics are the most common causes of DIILD

- $\quad$ Risks are highest when causative agents are used in combination

- $\quad$ Some, but not all, drugs are associated with a dose-dependent risk of DIILD

- Presentations and outcomes can vary even with the same agent

What are the risk factors for developing DIILD?

- Smoking and pre-existing lung disease are significant risk factors for many agents

- Other risk factors for some, but not all, drugs are increasing patient age, drug dose, male gender, prior therapy, high alcohol intake, presence of comorbid conditions and genetic susceptibility factors

Radiological investigation of DIILD and the prevalent radiopathological patterns

- $\quad$ Plain chest X-ray is often normal at presentation in DIILD

- $\quad \mathrm{CT}$ is the imaging modality of choice in DIILD

- $\quad$ CT alone cannot discriminate between DIILD and other types of ILD

- Different radiopathological patterns of ILD can occur with the same causative agent

- No characteristic radiopathological findings are characteristic or pathognomic of DIILD, but OP, followed by NSIP and HP, are the most frequently seen patterns

What is the role of non-imaging diagnostic investigations?

- $\quad$ Lung biopsy is not routinely indicated for investigation of DIILD

- BAL is an important investigation for the exclusion of infection

- $\quad$ There are currently no validated circulating biomarkers for the diagnosis or prognosis of DIILD

What is the impact of glucocorticoid (GC) therapy on DIILD outcome?

- There are no robust or comparative studies evaluating the adjunctive role of GC therapy alongside withdrawal of the causative drug

- There is low-quality evidence to support the efficacy and dosing of corticosteroids by grade of severity and radiopathological subtype of DIILD

- A pragmatic approach to use of GC is warranted, but further prospective studies are required to investigate further

What if any factors predict prognosis?

- $\quad$ Prognosis is highly variable between agents and patient populations

- DAD pattern of DIILD is associated with high mortality, but CT pattern alone is not consistently found to be a predictor of mortality

- $\quad$ Severity at presentation and acute onset are the most consistent predictors of mortality 
Author Contributions: Conceptualization, S.S., N.W., N.C., S.B., C.L., J.C.W., J.W., Methodology, S.S., N.W., N.C., S.B., C.L., J.C.W., J.W., K.L., I.N.B., Abstract reviews: S.S., N.C., S.B. Paper reviews, grading and arbitration: S.S., N.W., A.J.S., A.O., C.J., J.W., J.C.W., M.B., K.L., I.N.B., C.L., S.B., N.C., Project administration S.S., data curation S.S., Assimilation of data S.S., N.W., A.J.S., A.O., C.J., J.W., J.C.W., M.B., K.L., I.N.B., C.L., S.B., N.C., A.G., C.H., writing and original draft preparation S.S., N.W., A.J.S., A.O., C.J., J.W., J.C.W., M.B., K.L., I.N.B., C.L., S.B., N.C., A.G., C.H., writing reviewing and editing S.S., N.W., A.J.S., A.O., C.J., J.W., J.C.W., M.B., K.L., I.N.B., C.L., S.B., N.C., A.G., C.H.

Funding: This research was funded by Innovative Medicines Initiatives 2 Joint Undertaking under grant agreement No. 116106. This Joint Undertaking receives support from the European Union's Horizon 2020 research and innovation programme and EFPIA.

Acknowledgments: We are very grateful for the review and advice kindly provided by Philippe Camus, Centre Hospitalier Universitaire de Dijon. This work was also supported by the NIHR Manchester Biomedical Research Centre. Professor Bruce is an NIHR Senior Investigator. The views expressed in this publication are those of the author(s) and not necessarily those of the NHS, the National Institute for Health Research or the Department of Health.

Conflicts of Interest: J.C.W. reports grants from the Innovative Medicines Initiatives 2 Joint Undertaking under grant agreement No. 116106 (this Joint Undertaking receives support from the European Union's Horizon 2020 research and innovation programme and EFPIA), during the conduct of the study; personal fees from Bioxydyn Ltd., outside the submitted work; N.C. reports grants from Boehringer Ingelheim, personal fees from Roche, personal fees from Intermune, outside the submitted work; I.N.B. reports grants and other from GSK, grants from UCB Pharma, other from Merck Serono, other from Astra Zeneca, other from Eli Lilly, grants from Genzyme Sanofi, outside the submitted work.

\section{References}

1. Travis, W.D.; Costabel, U.; Hansell, D.M.; King, T.E., Jr.; Lynch, D.A.; Nicholson, A.G.; Ryerson, C.J.; Ryu, J.H.; Selman, M.I.; Wells, A.U.; et al. An official American Thoracic Society/European Respiratory Society statement: Update of the international multidisciplinary classification of the idiopathic interstitial pneumonias. Am. J. Respir. Crit. Care Med. 2013, 188, 733-748. [CrossRef] [PubMed]

2. Cancer Therapy Evaluation Program DoCTaDNCINIoH. Common Terminology Criteria for Adverse Events [Internet]. Version 5.0. 27-11-2017. Available online: http://ctep.cancer.gov (accessed on 13 October 2018).

3. Moher, D.; Liberati, A.; Tetzlaff, J.; Altman, D.G. Preferred reporting items for systematic reviews and meta-analyses: The PRISMA statement. J. Clin. Epidemiol. 2009, 62, 1006-1012. [CrossRef] [PubMed]

4. Guyatt, G.H.; Oxman, A.D.; Schunemann, H.J.; Tugwell, P.; Knottnerus, A. GRADE guidelines: A new series of articles in the Journal of Clinical Epidemiology. J. Clin. Epidemiol. 2011, 64, 380-382. [CrossRef] [PubMed]

5. Koo, L.C.; Clark, J.A.; Quesenberry, C.P.; Higenbottam, T.; Nyberg, F.; Wolf, M.K.; Steinberg, M.H.; Forsythe, B.H. National differences in reporting 'pneumonia' and 'pneumonia interstitial': An analysis of the WHO International Drug Monitoring Database on 15 drugs in nine countries for seven pulmonary conditions. Pharmacoepidemiol. Drug Saf. 2005, 14, 775-787. [CrossRef] [PubMed]

6. Bate, A.; Evans, S.J. Quantitative signal detection using spontaneous ADR reporting. Pharmacoepidemiol. Drug Saf. 2009, 18, 427-436. [CrossRef] [PubMed]

7. Amar, R.K.; Jick, S.S.; Rosenberg, D.; Maher, T.M.; Meier, C.R. Drug-/radiation-induced interstitial lung disease in the United Kingdom general population: Incidence, all-cause mortality and characteristics at diagnosis. Respirology 2012, 17, 861-868. [CrossRef] [PubMed]

8. Duchemann, B.; Annesi-Maesano, I.; de Jacobe, N.C.; Sanyal, S.; Brillet, P.Y.; Brauner, M.; Kambouchner, M.; Huynh, S.; Naccache, J.M.; Borie, R.; et al. Prevalence and incidence of interstitial lung diseases in a multi-ethnic county of Greater Paris. Eur. Respir. J. 2017, 50, 1602419. [CrossRef] [PubMed]

9. Coultas, D.B.; Zumwalt, R.E.; Black, W.C.; Sobonya, R.E. The epidemiology of interstitial lung diseases. Am. J. Respir. Crit. Care Med. 1994, 150, 967-972. [CrossRef] [PubMed]

10. Roelandt, M.; Demedts, M.; Callebaut, W.; Coolen, D.; Slabbynck, H.; Bockaert, J.; Kips, J.; Brie, J.; Ulburghs, M.; de Boeck, K.; et al. Epidemiology of interstitial lung disease (ILD) in flanders: Registration by pneumologists in 1992-1994. Working group on ILD, VRGT. Vereniging voor Respiratoire Gezondheidszorg en Tuberculosebestrijding. Acta Clin. Belg. 1995, 50, 260-268. [CrossRef] [PubMed]

11. Hyldgaard, C.; Hilberg, O.; Muller, A.; Bendstrup, E. A cohort study of interstitial lung diseases in central Denmark. Respir. Med. 2014, 108, 793-799. [CrossRef] [PubMed] 
12. Kakugawa, T.; Yokota, S.; Ishimatsu, Y.; Hayashi, T.; Nakashima, S.; Hara, S.; Sakamoto, N.; Matsuoka, Y.; Kubota, H.; Mine, M.; et al. Serum heat shock protein 47 levels in patients with drug-induced lung disease. Respir. Res. 2013, 14, 133. [CrossRef] [PubMed]

13. Tamura, M.; Saraya, T.; Fujiwara, M.; Hiraoka, S.; Yokoyama, T.; Yano, K.; Ishii, H.; Furuse, J.; Goya, T.; Takizawa, H.; et al. High-resolution computed tomography findings for patients with drug-induced pulmonary toxicity, with special reference to hypersensitivity pneumonitis-like patterns in gemcitabine-induced cases. Oncologist 2013, 18, 454-459. [CrossRef] [PubMed]

14. Ohnishi, H.; Yokoyama, A.; Yasuhara, Y.; Watanabe, A.; Naka, T.; Hamada, H.; Abe, M.; Nishimura, K.; Higaki, J.; Ikezoe, J.; et al. Circulating KL-6 levels in patients with drug induced pneumonitis. Thorax 2003, 58, 872-875. [CrossRef] [PubMed]

15. Piciucchi, S.; Romagnoli, M.; Chilosi, M.; Bigliazzi, C.; Dubini, A.; Beomonte, Z.B.; Gavelli, G.; Carloni, A.; Poletti, V. Prospective evaluation of drug-induced lung toxicity with high-resolution CT and transbronchial biopsy. Radiol. Med. 2011, 116, 246-263. [CrossRef] [PubMed]

16. Romagnoli, M.; Bigliazzi, C.; Casoni, G.; Chilosi, M.; Carloni, A.; Dubini, A.; Gurioli, C.; Tomassetti, S.; Gurioli, C.; Poletti, V. The role of transbronchial lung biopsy for the diagnosis of diffuse drug-induced lung disease: A case series of 44 patients. Sarcoidosis Vasc. Diffuse Lung Dis. 2008, 25, 36-45. [PubMed]

17. Akira, M.; Ishikawa, H.; Yamamoto, S. Drug-induced pneumonitis: Thin-section CT findings in 60 patients. Radiology 2002, 224, 852-860. [CrossRef] [PubMed]

18. Blum, R.H.; Carter, S.K.; Agre, K. A clinical review of bleomycin-A new antineoplastic agent. Cancer 1973, 31, 903-914. [CrossRef]

19. Delanoy, N.; Pecuchet, N.; Fabre, E.; Combe, P.; Juvin, K.; Pujade-Lauraine, E.; Oudard, S. Bleomycin-Induced Pneumonitis in the Treatment of Ovarian Sex Cord-Stromal Tumors: A Systematic Review and Meta-analysis. Int. J. Gynecol. Cancer 2015, 25, 1593-1598. [CrossRef] [PubMed]

20. Hubbard, S.P.; Chabner, B.A.; Canellos, G.P.; Young, R.C.; DeVita, V.T., Jr. High dose intravenous bleomycin in the treatment of advanced lymphomas. Eur. J. Cancer 1975, 11, 623-626. [CrossRef]

21. Ngeow, J.; Tan, I.B.; Kanesvaran, R.; Tan, H.C.; Tao, M.; Quek, R.; Lim, S.T. Prognostic impact of bleomycin-induced pneumonitis on the outcome of Hodgkin's lymphoma. Ann. Hematol. 2011, 90, 67-72. [CrossRef] [PubMed]

22. Stamatoullas, A.; Brice, P.; Bouabdallah, R.; Mareschal, S.; Camus, V.; Rahal, I.; Franchi, P.; Lanic, H.; Tilly, H. Outcome of patients older than 60 years with classical Hodgkin lymphoma treated with front line ABVD chemotherapy: Frequent pulmonary events suggest limiting the use of bleomycin in the elderly. Br. J. Haematol. 2015, 170, 179-184. [CrossRef] [PubMed]

23. O'Sullivan, J.M.; Huddart, R.A.; Norman, A.R.; Nicholls, J.; Dearnaley, D.P.; Horwich, A. Predicting the risk of bleomycin lung toxicity in patients with germ-cell tumours. Ann. Oncol. 2003, 14, 91-96. [CrossRef] [PubMed]

24. Johnson, P.; Federico, M.; Kirkwood, A.; Fossa, A.; Berkahn, L.; Carella, A.; d'Amore, F.; Enblad, G.; Franceschetto, A.; Fulham, M.; et al. Adapted Treatment Guided by Interim PET-CT Scan in Advanced Hodgkin's Lymphoma. N. Engl. J. Med. 2016, 374, 2419-2429. [CrossRef] [PubMed]

25. Wang, Y.; Hu, G.F.; Zhang, Q.Q.; Tang, N.; Guo, J.; Liu, L.Y.; Han, X.; Wang, X.; Wang, Z. Efficacy and safety of gemcitabine plus erlotinib for locally advanced or metastatic pancreatic cancer: A systematic review and meta-analysis. Drug Des. Dev. Ther. 2016, 10, 1961-1972. [CrossRef] [PubMed]

26. Sahin, I.H.; Geyer, A.I.; Kelly, D.W.; O’Reilly, E.M. Gemcitabine-Related Pneumonitis in Pancreas Adenocarcinoma-An Infrequent Event: Elucidation of Risk Factors and Management Implications. Clin. Colorectal. Cancer 2016, 15, 24-31. [CrossRef] [PubMed]

27. Yang, Z.Y.; Yuan, J.Q.; Di, M.Y.; Zheng, D.Y.; Chen, J.Z.; Ding, H.; Wu, X.Y.; Huang, Y.-F.; Mao, C.; Tang, J.-L. Gemcitabine plus erlotinib for advanced pancreatic cancer: A systematic review with meta-analysis. PLoS ONE 2013, 8, e57528. [CrossRef] [PubMed]

28. Bhatia, S.; Hanna, N.; Ansari, R.; Pletcher, W.; Einhorn, L.; Ng, E.; Sandlere, A. A phase II study of weekly gemcitabine and paclitaxel in patients with previously untreated stage IIIb and IV non-small cell lung cancer. Lung Cancer 2002, 38, 73-77. [CrossRef] 
29. Kouroussis, C.; Mavroudis, D.; Kakolyris, S.; Voloudaki, A.; Kalbakis, K.; Souglakos, J.; Agelaki, S.; Malas, K.; Bozionelou, V.; Georgoulias, V. High incidence of pulmonary toxicity of weekly docetaxel and gemcitabine in patients with non-small cell lung cancer: Results of a dose-finding study. Lung Cancer 2004, 44, 363-368. [CrossRef] [PubMed]

30. Hamada, T.; Yasunaga, H.; Nakai, Y.; Isayama, H.; Matsui, H.; Fushimi, K.; Koike, K. Interstitial lung disease associated with gemcitabine: A Japanese retrospective cohort study. Respirology 2016, 21, 338-343. [CrossRef] [PubMed]

31. Friedberg, J.W.; Neuberg, D.; Kim, H.; Miyata, S.; McCauley, M.; Fisher, D.C.; Takvorian, T.; Canellos, G.P. Gemcitabine added to doxorubicin, bleomycin, and vinblastine for the treatment of de novo Hodgkin disease: Unacceptable acute pulmonary toxicity. Cancer 2003, 98, 978-982. [CrossRef] [PubMed]

32. Umemura, S.; Yamane, H.; Suwaki, T.; Katoh, T.; Yano, T.; Shiote, Y.; Takigawa, N.; Kiura, K.; Kamei, H. Interstitial lung disease associated with gemcitabine treatment in patients with non-small-cell lung cancer and pancreatic cancer. J. Cancer Res. Clin. Oncol. 2011, 137, 1469-1475. [CrossRef] [PubMed]

33. Osawa, M.; Kudoh, S.; Sakai, F.; Endo, M.; Hamaguchi, T.; Ogino, Y.; Yoneoka, M.; Sakaguchi, M.; Nishimoto, H.; Gemma, A. Clinical features and risk factors of panitumumab-induced interstitial lung disease: A postmarketing all-case surveillance study. Int. J. Clin. Oncol. 2015, 20, 1063-1071. [CrossRef] [PubMed]

34. Gemma, A.; Kudoh, S.; Ando, M.; Ohe, Y.; Nakagawa, K.; Johkoh, T.; Yamazaki, N.; Arakawa, H.; Inoue, Y.; Ebina, M.; et al. Final safety and efficacy of erlotinib in the phase 4 POLARSTAR surveillance study of 10,708 Japanese patients with non-small-cell lung cancer. Cancer Sci. 2014, 105, 1584-1590. [CrossRef] [PubMed]

35. Shi, L.; Tang, J.; Tong, L.; Liu, Z. Risk of interstitial lung disease with gefitinib and erlotinib in advanced non-small cell lung cancer: A systematic review and meta-analysis of clinical trials. Lung Cancer 2014, 83, 231-239. [CrossRef] [PubMed]

36. Qi, W.X.; Sun, Y.J.; Shen, Z.; Yao, Y. Risk of interstitial lung disease associated with EGFR-TKIs in advanced non-small-cell lung cancer: A meta-analysis of 24 phase III clinical trials. J. Chemother. 2015, 27, 40-51. [CrossRef] [PubMed]

37. Kudoh, S.; Kato, H.; Nishiwaki, Y.; Fukuoka, M.; Nakata, K.; Ichinose, Y.; Tsuboi, M.; Yokota, S.; Nakagawa, K.; Suga, M.; et al. Interstitial lung disease in Japanese patients with lung cancer: A cohort and nested case-control study. Am. J. Respir. Crit. Care Med. 2008, 177, 1348-1357. [CrossRef] [PubMed]

38. Ishiguro, M.; Watanabe, T.; Yamaguchi, K.; Satoh, T.; Ito, H.; Seriu, T.; Sakata, Y.; Sugihara, K. A Japanese post-marketing surveillance of cetuximab $(\operatorname{Erbitux}(\mathrm{R}))$ in patients with metastatic colorectal cancer. Jpn. J. Clin. Oncol. 2012, 42, 287-294. [CrossRef] [PubMed]

39. Boku, N.; Sugihara, K.; Kitagawa, Y.; Hatake, K.; Gemma, A.; Yamazaki, N.; Muro, K.; Hamaguchi, T.; Yoshino, T.; Yana, I.; et al. Panitumumab in Japanese patients with unresectable colorectal cancer: A post-marketing surveillance study of 3085 patients. Jpn. J. Clin. Oncol. 2014, 44, 214-223. [CrossRef] [PubMed]

40. Liu, C.T.; Chen, M.H.; Chen, J.S.; Chen, L.T.; Shan, Y.S.; Lu, C.H.; Su, Y.-L.; Ku, F.-C.; Chou, W.-C.; Chen, Y.-Y. The efficacy and safety of everolimus for the treatment of progressive gastroenteropancreatic neuroendocrine tumors: A multi-institution observational study in Taiwan. Asia Pac. J. Clin. Oncol. 2016, 12, 396-402. [CrossRef] [PubMed]

41. Solazzo, A.; Botta, C.; Nava, F.; Baisi, A.; Bonucchi, D.; Cappelli, G. Interstitial Lung Disease After Kidney Transplantation and the Role of Everolimus. Transplant. Proc. 2016, 48, 349-351. [CrossRef] [PubMed]

42. Nishino, M.; Brais, L.K.; Brooks, N.V.; Hatabu, H.; Kulke, M.H.; Ramaiya, N.H. Drug-related pneumonitis during mammalian target of rapamycin inhibitor therapy in patients with neuroendocrine tumors: A radiographic pattern-based approach. Eur. J. Cancer 2016, 53, 163-170. [CrossRef] [PubMed]

43. Nishino, M.; Boswell, E.N.; Hatabu, H.; Ghobrial, I.M.; Ramaiya, N.H. Drug-Related Pneumonitis During Mammalian Target of Rapamycin Inhibitor Therapy: Radiographic Pattern-Based Approach in Waldenstrom Macroglobulinemia as a Paradigm. Oncologist 2015, 20, 1077-1083. [CrossRef] [PubMed]

44. Duran, I.; Siu, L.L.; Oza, A.M.; Chung, T.B.; Sturgeon, J.; Townsley, C.A.; Pond, G.R.; Seymour, L.; Niroumand, M. Characterisation of the lung toxicity of the cell cycle inhibitor temsirolimus. Eur. J. Cancer 2006, 42, 1875-1880. [CrossRef] [PubMed] 
45. White, D.A.; Camus, P.; Endo, M.; Escudier, B.; Calvo, E.; Akaza, H.; Uemura, H.; Kpamegan, E.; Kay, A.; Robson, M.; et al. Noninfectious pneumonitis after everolimus therapy for advanced renal cell carcinoma. Am. J. Respir. Crit. Care Med. 2010, 182, 396-403. [CrossRef] [PubMed]

46. Iacovelli, R.; Palazzo, A.; Mezi, S.; Morano, F.; Naso, G.; Cortesi, E. Incidence and risk of pulmonary toxicity in patients treated with mTOR inhibitors for malignancy. A meta-analysis of published trials. Acta Oncol. 2012, 51, 873-879. [CrossRef] [PubMed]

47. Maroto, J.P.; Hudes, G.; Dutcher, J.P.; Logan, T.F.; White, C.S.; Krygowski, M.; Cincotta, M.; Shapiro, M.; Duran, I.; Berkenblit, A. Drug-related pneumonitis in patients with advanced renal cell carcinoma treated with temsirolimus. J. Clin. Oncol. 2011, 29, 1750-1756. [CrossRef] [PubMed]

48. Rodriguez-Moreno, A.; Ridao, N.; Garcia-Ledesma, P.; Calvo, N.; Perez-Flores, I.; Marques, M.; Barrientos, A.; Sánchez-Fructuoso, A.I. Sirolimus and everolimus induced pneumonitis in adult renal allograft recipients: Experience in a center. Transplant. Proc. 2009, 41, 2163-2165. [CrossRef] [PubMed]

49. Baas, M.C.; Struijk, G.H.; Moes, D.J.; Van den Berk, I.A.; Jonkers, R.E.; De Fijter, J.W.; van der Heide, J.J.H.; van Dijk, M.; ten Berge, I.J.M.; Bemelman, F.J. Interstitial pneumonitis caused by everolimus: A case-cohort study in renal transplant recipients. Transpl. Int. 2014, 27, 428-436. [CrossRef] [PubMed]

50. Hodi, F.S.; O’Day, S.J.; McDermott, D.F.; Weber, R.W.; Sosman, J.A.; Haanen, J.B.; Gonzalez, R.; Robert, C.; Schadendorf, D.; Hassel, J.C.; et al. Improved survival with ipilimumab in patients with metastatic melanoma. N. Engl. J. Med. 2010, 363, 711-723. [CrossRef] [PubMed]

51. Delaunay, M.; Cadranel, J.; Lusque, A.; Meyer, N.; Gounant, V.; Moro-Sibilot, D.; Michot, J.-M.; Raimbourg, J.; Girard, N.; Guisier, F.; et al. Immune-checkpoint inhibitors associated with interstitial lung disease in cancer patients. Eur. Respir. J. 2017, 50, 1700050. [CrossRef] [PubMed]

52. Khunger, M.; Rakshit, S.; Pasupuleti, V.; Hernandez, A.V.; Mazzone, P.; Stevenson, J.; Pennell, N.A.; Velcheti, V. Incidence of Pneumonitis with Use of Programmed Death 1 and Programmed Death-Ligand 1 Inhibitors in Non-Small Cell Lung Cancer: A Systematic Review and Meta-Analysis of Trials. Chest 2017, 152, $271-281$. [CrossRef] [PubMed]

53. Nishino, M.; Giobbie-Hurder, A.; Hatabu, H.; Ramaiya, N.H.; Hodi, F.S. Incidence of Programmed Cell Death 1 Inhibitor-Related Pneumonitis in Patients with Advanced Cancer: A Systematic Review and Meta-analysis. JAMA Oncol. 2016, 2, 1607-1616. [CrossRef] [PubMed]

54. Wolchok, J.D.; Chiarion-Sileni, V.; Gonzalez, R.; Rutkowski, P.; Grob, J.J.; Cowey, C.L.; Lao, C.D.; Wagstaff, J.; Schadendorf, D.; Ferrucci, P.F.; et al. Overall Survival with Combined Nivolumab and Ipilimumab in Advanced Melanoma. N. Engl. J. Med. 2017, 377, 1345-1356. [CrossRef] [PubMed]

55. Conway, R.; Low, C.; Coughlan, R.J.; O’Donnell, M.J.; Carey, J.J. Methotrexate and lung disease in rheumatoid arthritis: A meta-analysis of randomized controlled trials. Arthritis Rheumatol. 2014, 66, 803-812. [CrossRef] [PubMed]

56. Drosos, A.A.; Psychos, D.; Andonopoulos, A.P.; Stefanaki-Nikou, S.; Tsianos, E.B.; Moutsopoulos, H.M. Methotrexate therapy in rheumatoid arthritis: A two year prospective follow-up. Clin. Rheumatol. 1990, 9, 333-341. [CrossRef] [PubMed]

57. Conway, R.; Low, C.; Coughlan, R.J.; O'Donnell, M.J.; Carey, J.J. Methotrexate use and risk of lung disease in psoriasis, psoriatic arthritis, and inflammatory bowel disease: Systematic literature review and meta-analysis of randomised controlled trials. BMJ 2015, 350, 1269. [CrossRef] [PubMed]

58. Alarcon, G.S.; Kremer, J.M.; Macaluso, M.; Weinblatt, M.E.; Cannon, G.W.; Palmer, W.R.; St. Clair, E.W.; Sundy, J.S.; Alexander, R.W.; Smith, G.J.W.; et al. Risk factors for methotrexate-induced lung injury in patients with rheumatoid arthritis. A multicenter, case-control study. Methotrexate-Lung Study Group. Ann. Intern. Med. 1997, 127, 356-364. [CrossRef] [PubMed]

59. Sharma, A.; Provenzale, D.; McKusick, A.; Kaplan, M.M. Interstitial pneumonitis after low-dose methotrexate therapy in primary biliary cirrhosis. Gastroenterology 1994, 107, 266-270. [CrossRef]

60. Imokawa, S.; Colby, T.V.; Leslie, K.O.; Helmers, R.A. Methotrexate pneumonitis: Review of the literature and histopathological findings in nine patients. Eur. Respir. J. 2000, 15, 373-381. [CrossRef] [PubMed]

61. Kremer, J.M.; Alarcon, G.S.; Weinblatt, M.E.; Kaymakcian, M.V.; Macaluso, M.; Cannon, G.W.; Palmer, W.R.; Sundy, J.S.; St Clair, E.W.; Alexander, R.W.; et al. Clinical, laboratory, radiographic, and histopathologic features of methotrexate-associated lung injury in patients with rheumatoid arthritis: A multicenter study with literature review. Arthritis Rheum. 1997, 40, 1829-1837. [CrossRef] [PubMed] 
62. Sawada, T.; Inokuma, S.; Sato, T.; Otsuka, T.; Saeki, Y.; Takeuchi, T.; Matsuda, T.; Takemura, T.; Sagawa, A.; On Behalf of the Study Committee for Leflunomide-induced Lung Injury, Japan College of Rheumatology. Leflunomide-induced interstitial lung disease: Prevalence and risk factors in Japanese patients with rheumatoid arthritis. Rheumatology 2009, 48, 1069-1072. [CrossRef] [PubMed]

63. Chikura, B.; Lane, S.; Dawson, J.K. Clinical expression of leflunomide-induced pneumonitis. Rheumatology 2009, 48, 1065-1068. [CrossRef] [PubMed]

64. Sato, T.; Inokuma, S.; Sagawa, A.; Matsuda, T.; Takemura, T.; Otsuka, T.; Saeki, Y.; Takeuchi, T.; Sawada, T.; On Behalf of the Study Committee for Leflunomide-induced Lung Injury, Japan College of Rheumatology. Factors associated with fatal outcome of leflunomide-induced lung injury in Japanese patients with rheumatoid arthritis. Rheumatology 2009, 48, 1265-1268. [CrossRef] [PubMed]

65. Suissa, S.; Hudson, M.; Ernst, P. Leflunomide use and the risk of interstitial lung disease in rheumatoid arthritis. Arthritis Rheum. 2006, 54, 1435-1439. [CrossRef] [PubMed]

66. Conway, R.; Low, C.; Coughlan, R.J.; O’Donnell, M.J.; Carey, J.J. Leflunomide Use and Risk of Lung Disease in Rheumatoid Arthritis: A Systematic Literature Review and Metaanalysis of Randomized Controlled Trials. J. Rheumatol. 2016, 43, 855-860. [CrossRef] [PubMed]

67. Roubille, C.; Haraoui, B. Interstitial lung diseases induced or exacerbated by DMARDS and biologic agents in rheumatoid arthritis: A systematic literature review. Semin. Arthritis Rheum. 2014, 43, 613-626. [CrossRef] [PubMed]

68. Koike, T.; Harigai, M.; Ishiguro, N.; Inokuma, S.; Takei, S.; Takeuchi, T.; Yamanaka, H.; Tanaka, Y. Safety and effectiveness of adalimumab in Japanese rheumatoid arthritis patients: Postmarketing surveillance report of the first 3000 patients. Mod. Rheumatol. 2012, 22, 498-508. [CrossRef] [PubMed]

69. Herrinton, L.J.; Harrold, L.R.; Liu, L.; Raebel, M.A.; Taharka, A.; Winthrop, K.L.; Solomon, D.H.; Curtis, J.R.; Lewis, J.D.; Saag, K.G. Association between anti-TNF-alpha therapy and interstitial lung disease. Pharmacoepidemiol. Drug Saf. 2013, 22, 394-402. [CrossRef] [PubMed]

70. Curtis, J.R.; Sarsour, K.; Napalkov, P.; Costa, L.A.; Schulman, K.L. Incidence and complications of interstitial lung disease in users of tocilizumab, rituximab, abatacept and anti-tumor necrosis factor alpha agents, a retrospective cohort study. Arthritis Res. Ther. 2015, 17, 319. [CrossRef] [PubMed]

71. Perez-Alvarez, R.; Perez-de-Lis, M.; Diaz-Lagares, C.; Pego-Reigosa, J.M.; Retamozo, S.; Bove, A.; Brito-Zeron, P.; Bosch, X.; Ramos-Casals, M. Interstitial lung disease induced or exacerbated by TNF-targeted therapies: Analysis of 122 cases. Semin. Arthritis Rheum. 2011, 41, 256-264. [CrossRef] [PubMed]

72. Hadjinicolaou, A.V.; Nisar, M.K.; Bhagat, S.; Parfrey, H.; Chilvers, E.R.; Ostor, A.J. Non-infectious pulmonary complications of newer biological agents for rheumatic diseases-A systematic literature review. Rheumatology 2011, 50, 2297-2305. [CrossRef] [PubMed]

73. Liote, H.; Liote, F.; Seroussi, B.; Mayaud, C.; Cadranel, J. Rituximab-induced lung disease: A systematic literature review. Eur. Respir. J. 2010, 35, 681-687. [CrossRef] [PubMed]

74. Wagner, S.A.; Mehta, A.C.; Laber, D.A. Rituximab-induced interstitial lung disease. Am. J. Hematol. 2007, 82, 916-919. [CrossRef] [PubMed]

75. Penn, R.G.; Griffin, J.P. Adverse reactions to nitrofurantoin in the United Kingdom, Sweden, and Holland. Br. Med. J. 1982, 284, 1440-1442. [CrossRef]

76. Holmberg, L.; Boman, G.; Bottiger, L.E.; Eriksson, B.; Spross, R.; Wessling, A. Adverse reactions to nitrofurantoin. Analysis of 921 reports. Am. J. Med. 1980, 69, 733-738. [CrossRef]

77. Sovijarvi, A.R.; Lemola, M.; Stenius, B.; Idanpaan-Heikkila, J. Nitrofurantoin-induced acute, subacute and chronic pulmonary reactions. Scand. J. Respir. Dis. 1977, 58, 41-50. [PubMed]

78. Santos, J.M.; Batech, M.; Pelter, M.A.; Deamer, R.L. Evaluation of the Risk of Nitrofurantoin Lung Injury and Its Efficacy in Diminished Kidney Function in Older Adults in a Large Integrated Healthcare System: A Matched Cohort Study. J. Am. Geriatr. Soc. 2016, 64, 798-805. [CrossRef] [PubMed]

79. Durante-Mangoni, E.; Andini, R.; Parrella, A.; Mattucci, I.; Cavezza, G.; Senese, A.; Trojaniello, C.; Caprioli, R.; Diana, M.V.; Utili, R. Safety of treatment with high-dose daptomycin in 102 patients with infective endocarditis. Int. J. Antimicrob. Agents 2016, 48, 61-68. [CrossRef] [PubMed]

80. Mankikian, J.; Favelle, O.; Guillon, A.; Guilleminault, L.; Cormier, B.; Jonville-Bera, A.P.; Perrotin, D.; Diot, P.; Marchand-Adam, S. Initial characteristics and outcome of hospitalized patients with amiodarone pulmonary toxicity. Respir. Med. 2014, 108, 638-646. [CrossRef] [PubMed] 
81. Bongard, V.; Marc, D.; Philippe, V.; Jean-Louis, M.; Maryse, L.M. Incidence rate of adverse drug reactions during long-term follow-up of patients newly treated with amiodarone. Am. J. Ther. 2006, 13, 315-319. [CrossRef] [PubMed]

82. Tisdale, J.E.; Follin, S.L.; Ordelova, A.; Webb, C.R. Risk factors for the development of specific noncardiovascular adverse effects associated with amiodarone. J. Clin. Pharmacol. 1995, 35, 351-356. [CrossRef] [PubMed]

83. Pollak, P.T.; Sharma, A.D.; Carruthers, S.G. Relation of amiodarone hepatic and pulmonary toxicity to serum drug concentrations and superoxide dismutase activity. Am. J. Cardiol. 1990, 65, 1185-1191. [CrossRef]

84. Kang, I.S.; Kim, K.J.; Kim, Y.; Park, S.H. The diagnostic utility of chest computed tomography scoring for the assessment of amiodarone-induced pulmonary toxicity. Korean J. Intern. Med. 2014, 29, 746-753. [CrossRef] [PubMed]

85. Yamada, Y.; Shiga, T.; Matsuda, N.; Hagiwara, N.; Kasanuki, H. Incidence and predictors of pulmonary toxicity in Japanese patients receiving low-dose amiodarone. Circ. J. 2007, 71, 1610-1616. [CrossRef] [PubMed]

86. Dusman, R.E.; Stanton, M.S.; Miles, W.M.; Klein, L.S.; Zipes, D.P.; Fineberg, N.S.; Heger, J.J. Clinical features of amiodarone-induced pulmonary toxicity. Circulation 1990, 82, 51-59. [CrossRef] [PubMed]

87. Dean, P.J.; Groshart, K.D.; Porterfield, J.G.; Iansmith, D.H.; Golden, E.B., Jr. Amiodarone-associated pulmonary toxicity. A clinical and pathologic study of eleven cases. Am. J. Clin. Pathol. 1987, 87, 7-13. [CrossRef] [PubMed]

88. Kupferschmid, J.P.; Rosengart, T.K.; McIntosh, C.L.; Leon, M.B.; Clark, R.E. Amiodarone-induced complications after cardiac operation for obstructive hypertrophic cardiomyopathy. Ann. Thorac. Surg. 1989, 48, 359-364. [CrossRef]

89. Logan, P.M.; Primack, S.L.; Staples, C.; Miller, R.R.; Muller, N.L. Acute lung disease in the immunocompromised host. Diagnostic accuracy of the chest radiograph. Chest 1995, 108, 1283-1287. [CrossRef] [PubMed]

90. Kawase, S.; Hattori, N.; Ishikawa, N.; Horimasu, Y.; Fujitaka, K.; Furonaka, O.; Isobe, T.; Miyoshi, S.; Hamada, H.; Yamane, T.; et al. Change in serum KL-6 level from baseline is useful for predicting life-threatening EGFR-TKIs induced interstitial lung disease. Respir. Res. 2011, 12, 97. [CrossRef] [PubMed]

91. Tirumani, S.H.; Ramaiya, N.H.; Keraliya, A.; Bailey, N.D.; Ott, P.A.; Hodi, F.S.; Nishino, M. Radiographic Profiling of Immune-Related Adverse Events in Advanced Melanoma Patients Treated with Ipilimumab. Cancer Immunol. Res. 2015, 3, 1185-1192. [CrossRef] [PubMed]

92. Nishino, M.; Ramaiya, N.H.; Awad, M.M.; Sholl, L.M.; Maattala, J.A.; Taibi, M.; Hatabu, H.; Ott, P.A.; Armand, P.; Hodi, F.S. PD-1 Inhibitor-Related Pneumonitis in Advanced Cancer Patients: Radiographic Patterns and Clinical Course. Clin. Cancer Res. 2016, 22, 6051-6060. [CrossRef] [PubMed]

93. Yoshii, N.; Suzuki, T.; Nagashima, M.; Kon, A.; Kakihata, K.; Gemma, A. Clarification of clinical features of interstitial lung disease induced by irinotecan based on postmarketing surveillance data and spontaneous reports. Anti-Cancer Drugs 2011, 22, 563-568. [CrossRef] [PubMed]

94. Ohnishi, K.; Sakai, F.; Kudoh, S.; Ohno, R. Twenty-seven cases of drug-induced interstitial lung disease associated with imatinib mesylate. Leukemia 2006, 20, 1162-1164. [CrossRef] [PubMed]

95. Tomii, K.; Kato, T.; Takahashi, M.; Noma, S.; Kobashi, Y.; Enatsu, S.; Okubo, S.; Kobayashi, N.; Kudoh, S. Pemetrexed-related interstitial lung disease reported from post marketing surveillance (malignant pleural mesothelioma/non-small cell lung cancer). Jpn. J. Clin. Oncol. 2017, 47, 350-356. [CrossRef] [PubMed]

96. Iki, S.; Yoshinaga, K.; Ohbayashi, Y.; Urabe, A. Cytotoxic drug-induced pneumonia and possible augmentation by G-CSF-Clinical attention. Ann. Hematol. 1993, 66, 217-218. [CrossRef] [PubMed]

97. Koike, T.; Harigai, M.; Inokuma, S.; Ishiguro, N.; Ryu, J.; Takeuchi, T.; Tanaka, Y.; Yamanaka, H.; Fujii, K.; Yoshinaga, T.; et al. Postmarketing surveillance of safety and effectiveness of etanercept in Japanese patients with rheumatoid arthritis. Mod. Rheumatol. 2011, 21, 343-351. [CrossRef] [PubMed]

98. Ramos-Casals, M.; Brito-Zeron, P.; Munoz, S.; Soria, N.; Galiana, D.; Bertolaccini, L.; Cuadrado, M.-J.; Khamashta, M.A. Autoimmune diseases induced by TNF-targeted therapies: Analysis of 233 cases. Medicine 2007, 86, 242-251. [CrossRef] [PubMed]

99. Israel-Biet, D.; Venet, A.; Caubarrere, I.; Bonan, G.; Danel, C.; Chretien, J.; Hance, A.J. Bronchoalveolar lavage in amiodarone pneumonitis. Cellular abnormalities and their relevance to pathogenesis. Chest 1987, 91, 214-221. [CrossRef] [PubMed] 
100. Waxman, H.L.; Groh, W.C.; Marchlinski, F.E.; Buxton, A.E.; Sadowski, L.M.; Horowitz, L.N.; Josephson, M.E.; Kastor, J.A. Amiodarone for control of sustained ventricular tachyarrhythmia: Clinical and electrophysiologic effects in 51 patients. Am. J. Cardiol. 1982, 50, 1066-1074. [CrossRef]

101. Van, M.W.; Coolen, L.; Malysse, I.; Lacquet, L.M.; Deneffe, G.J.; Demedts, M.G. Amiodarone and the development of ARDS after lung surgery. Chest 1994, 105, 1642-1645.

102. Yamasaki, K.; Yatera, K.; Noguchi, S.; Oda, K.; Akata, K.; Nishida, C.; Kawanami, T.; Kawanami, Y.; Ishimoto, H.; Ono, S.; et al. Incidence and outcomes of bepridil-induced interstitial pneumonia. Respir. Med. 2013, 107, 2088-2091. [CrossRef] [PubMed]

103. Fernandez, A.B.; Karas, R.H.; Alsheikh-Ali, A.A.; Thompson, P.D. Statins and interstitial lung disease: A systematic review of the literature and of food and drug administration adverse event reports. Chest 2008, 134, 824-830. [CrossRef] [PubMed]

104. Hardak, E.; Berger, G.; Krivoy, N.; Solomonov, A.; Yigla, M. Nitrofurantoin pulmonary toxicity: Neglected threat. Curr. Drug Saf. 2010, 5, 125-128. [CrossRef] [PubMed]

105. Kim, P.W.; Sorbello, A.F.; Wassel, R.T.; Pham, T.M.; Tonning, J.M.; Nambiar, S. Eosinophilic pneumonia in patients treated with daptomycin: Review of the literature and US FDA adverse event reporting system reports. Drug Saf. 2012, 35, 447-457. [CrossRef] [PubMed]

106. Slavenburg, S.; Heijdra, Y.F.; Drenth, J.P. Pneumonitis as a consequence of (peg) interferon-ribavirin combination therapy for hepatitis C: A review of the literature. Dig. Dis. Sci. 2010, 55, 579-585. [CrossRef] [PubMed]

107. Minami-Shimmyo, Y.; Ohe, Y.; Yamamoto, S.; Sumi, M.; Nokihara, H.; Horinouchi, H.; Yamamoto, N.; Sekine, I.; Kubota, K.; Tamura, T. Risk factors for treatment-related death associated with chemotherapy and thoracic radiotherapy for lung cancer. J. Thorac. Oncol. 2012, 7, 177-182. [CrossRef] [PubMed]

108. Sakurada, T.; Kakiuchi, S.; Tajima, S.; Horinouchi, Y.; Okada, N.; Nishisako, H.; Nakamura, T.; Teraoka, K.; Kawazoe, K.; Yanagawa, H.; et al. Characteristics of and risk factors for interstitial lung disease induced by chemotherapy for lung cancer. Ann. Pharmacother. 2015, 49, 398-404. [CrossRef] [PubMed]

109. Johkoh, T.; Sakai, F.; Kusumoto, M.; Arakawa, H.; Harada, R.; Ueda, M.; Kudoh, S.; Fukuoka, M. Association between baseline pulmonary status and interstitial lung disease in patients with non-small-cell lung cancer treated with erlotinib-A cohort study. Clin. Lung Cancer 2014, 15, 448-454. [CrossRef] [PubMed]

110. Nakagawa, K.; Kudoh, S.; Ohe, Y.; Johkoh, T.; Ando, M.; Yamazaki, N.; Seki, A.; Takemoto, S.; Fukuoka, M. Postmarketing surveillance study of erlotinib in Japanese patients with non-small-cell lung cancer (NSCLC, an interim analysis of 3488 patients (POLARSTAR). J. Thorac. Oncol. 2012, 7, 1296-1303. [CrossRef] [PubMed]

111. Shidara, K.; Hoshi, D.; Inoue, E.; Yamada, T.; Nakajima, A.; Taniguchi, A.; Hara, M.; Momohara, S.; Kamatani, N.; Yamanaka, H. Incidence of and risk factors for interstitial pneumonia in patients with rheumatoid arthritis in a large Japanese observational cohort, IORRA. Mod. Rheumatol. 2010, 20, 280-286. [CrossRef] [PubMed]

112. Ando, M.; Okamoto, I.; Yamamoto, N.; Takeda, K.; Tamura, K.; Seto, T.; Ariyoshi, Y.; Fukuoka, M. Predictive factors for interstitial lung disease, antitumor response, and survival in non-small-cell lung cancer patients treated with gefitinib. J. Clin. Oncol. 2006, 24, 2549-2556. [CrossRef] [PubMed]

113. Wijnen, P.A.; Drent, M.; Nelemans, P.J.; Kuijpers, P.M.; Koek, G.H.; Neef, C.; Haenen, G.R.M.M.; Bekers, O. Role of cytochrome $\mathrm{P} 450$ polymorphisms in the development of pulmonary drug toxicity: A case-control study in The Netherlands. Drug Saf. 2008, 31, 1125-1134. [CrossRef] [PubMed]

114. Nishimura, M.; Toyoda, M.; Takenaka, K.; Imamura, Y.; Chayahara, N.; Kiyota, N.; Mukohara, T.; Kotake, T.; Tsuji, A.; Saito, K.; et al. The combination of HLA-B*15:01 and DRB1¹5:01 is associated with gemcitabine plus erlotinib-induced interstitial lung disease in patients with advanced pancreatic cancer. Cancer Chemother. Pharmacol. 2016, 77, 1165-1170. [CrossRef] [PubMed]

115. Weiner, S.M.; Sellin, L.; Vonend, O.; Schenker, P.; Buchner, N.J.; Flecken, M.; Viebahn, R.; Rump, L.C. Pneumonitis associated with sirolimus: Clinical characteristics, risk factors and outcome-A single-centre experience and review of the literature. Nephrol. Dial. Transplant. 2007, 22, 3631-3637. [CrossRef] [PubMed]

116. Chap, L.; Shpiner, R.; Levine, M.; Norton, L.; Lill, M.; Glaspy, J. Pulmonary toxicity of high-dose chemotherapy for breast cancer: A non-invasive approach to diagnosis and treatment. Bone Marrow Transplant. 1997, 20, 1063-1067. [CrossRef] [PubMed]

117. Padley, S.P.; Adler, B.; Hansell, D.M.; Muller, N.L. High-resolution computed tomography of drug-induced lung disease. Clin. Radiol. 1992, 46, 232-236. [CrossRef] 
118. Potente, G.; Bellelli, A.; Nardis, P. Specific diagnosis by CT and HRCT in six chronic lung diseases. Comput. Med. Imaging Graph. 1992, 16, 277-282. [CrossRef]

119. Cleverley, J.R.; Screaton, N.J.; Hiorns, M.P.; Flint, J.D.; Muller, N.L. Drug-induced lung disease: High-resolution CT and histological findings. Clin. Radiol. 2002, 57, 292-299. [CrossRef] [PubMed]

120. Patz, E.F., Jr.; Peters, W.P.; Goodman, P.C. Pulmonary drug toxicity following high-dose chemotherapy with autologous bone marrow transplantation: CT findings in 20 cases. J. Thorac. Imaging 1994, 9, 129-134. [CrossRef] [PubMed]

121. Nakamura, K.; Kato, M.; Shukuya, T.; Mori, K.; Sekimoto, Y.; Ihara, H.; Kanemaru, R.; Ko, R.; Shibayama, R.; Tajima, K.; et al. Surfactant protein-D predicts prognosis of interstitial lung disease induced by anticancer agents in advanced lung cancer: A case control study. BMC Cancer 2017, 17, 302. [CrossRef] [PubMed]

122. Takatani, K.; Miyazaki, E.; Nureki, S.; Ando, M.; Ueno, T.; Okubo, T.; Takenaka, R.; Hiroshige, S.; Kumamoto, T. High-resolution computed tomography patterns and immunopathogenetic findings in drug-induced pneumonitis. Respir. Med. 2008, 102, 892-898. [CrossRef] [PubMed]

123. Johkoh, T.; Itoh, H.; Muller, N.L.; Ichikado, K.; Nakamura, H.; Ikezoe, J.; Akira, M.; Nagareda, T. Crazy-paving appearance at thin-section CT: Spectrum of disease and pathologic findings. Radiology 1999, 211, 155-160. [CrossRef] [PubMed]

124. Jones, R.B.; Matthes, S.; Shpall, E.J.; Fisher, J.H.; Stemmer, S.M.; Dufton, C.; Stephens, J.K.; Bearman, S.I. Acute lung injury following treatment with high-dose cyclophosphamide, cisplatin, and carmustine: Pharmacodynamic evaluation of carmustine. J. Natl. Cancer Inst. 1993, 85, 640-647. [CrossRef] [PubMed]

125. Akoun, G.M.; Cadranel, J.L.; Milleron, B.J.; D’Ortho, M.P.; Mayaud, C.M. Bronchoalveolar lavage cell data in 19 patients with drug-associated pneumonitis (except amiodarone). Chest 1991, 99, 98-104. [CrossRef] [PubMed]

126. Allen, J.N.; Davis, W.B.; Pacht, E.R. Diagnostic significance of increased bronchoalveolar lavage fluid eosinophils. Am. Rev. Respir. Dis. 1990, 142, 642-647. [CrossRef] [PubMed]

127. White, D.A.; Rankin, J.A.; Stover, D.E.; Gellene, R.A.; Gupta, S. Methotrexate pneumonitis. Bronchoalveolar lavage findings suggest an immunologic disorder. Am. Rev. Respir. Dis. 1989, 139, 18-21. [CrossRef] [PubMed]

128. Fuhrman, C.; Parrot, A.; Wislez, M.; Prigent, H.; Boussaud, V.; Bernaudin, J.F.; Mayaud, C.; Cadranel, J. Spectrum of CD4 to CD8 T-cell ratios in lymphocytic alveolitis associated with methotrexate-induced pneumonitis. Am. J. Respir. Crit. Care Med. 2001, 164, 1186-1191. [CrossRef] [PubMed]

129. Akoun, G.M.; Mayaud, C.M.; Touboul, J.L.; Denis, M.F.; Milleron, B.J.; Perrot, J.Y. Use of bronchoalveolar lavage in the evaluation of methotrexate lung disease. Thorax 1987, 42, 652-655. [CrossRef] [PubMed]

130. Schnabel, A.; Richter, C.; Bauerfeind, S.; Gross, W.L. Bronchoalveolar lavage cell profile in methotrexate induced pneumonitis. Thorax 1997, 52, 377-379. [CrossRef] [PubMed]

131. Huang, M.S.; Colby, T.V.; Goellner, J.R.; Martin, W.J., Jr. Utility of bronchoalveolar lavage in the diagnosis of drug-induced pulmonary toxicity. Acta Cytol. 1989, 33, 533-538. [PubMed]

132. Lim, K.H.; Yoon, H.I.; Kang, Y.A.; Lee, K.W.; Kim, J.H.; Bang, S.M.; Lee, J.H.; Lee, C.-T.; Lee, J.S. Severe pulmonary adverse effects in lymphoma patients treated with cyclophosphamide, doxorubicin, vincristine, and prednisone (CHOP) regimen plus rituximab. Korean J. Intern. Med. 2010, 25, 86-92. [CrossRef] [PubMed]

133. Rebattu, P.; Quantin, X.; Ardiet, C.; Morere, J.F.; Azarian, M.R.; Schuller-Lebeau, M.P.; Pujol, J.-L. Dose-finding, pharmacokinetic and phase II study of docetaxel in combination with gemcitabine in patients with inoperable non-small cell lung cancer. Lung Cancer 2001, 33, 277-287. [CrossRef]

134. Ki, K.D.; Lee, J.M.; Lee, S.K.; Tong, S.Y.; Huh, C.Y.; Ryu, J.K.; Kim, K.-Y. Pulmonary toxicity after a quick course of combinatorial vincristine, bleomycin, and cisplatin neoadjuvant chemotherapy in cervical cancer. J. Korean Med. Sci. 2010, 25, 240-244. [CrossRef] [PubMed]

135. Vial-Dupuy, A.; Sanchez, O.; Douvry, B.; Guetta, L.; Juvin, K.; Wermert, D.; Guérot, E.; Israël-Biet, D. Outcome of patients with interstitial lung disease admitted to the intensive care unit. Sarcoidosis Vasc. Diffuse Lung Dis. 2013, 30, 134-142. [PubMed]

136. Park, S.Y.; Lim, S.Y.; Um, S.W.; Koh, W.J.; Chung, M.P.; Kim, H.; Kwon, O.J.; Park, H.K.; Kim, S.J.; Im, Y.H.; et al. Outcome and predictors of mortality in patients requiring invasive mechanical ventilation due to acute respiratory failure while undergoing ambulatory chemotherapy for solid cancers. Support. Care Cancer 2013, 21, 1647-1653. [CrossRef] [PubMed] 
137. Delorme, S.; Keller-Reichenbecher, M.A.; Zuna, I.; Schlegel, W.; Van, K.G. Usual interstitial pneumonia. Quantitative assessment of high-resolution computed tomography findings by computer-assisted texture-based image analysis. Investig. Radiol. 1997, 32, 566-574. [CrossRef]

138. Wild, J.M. Imaging pathophysiological changes in the lungs in IPF with xenon magnetic resonance imaging. Thorax 2018, 73, 1. [CrossRef] [PubMed]

139. Morgan, A.R.; Parker, G.J.; Roberts, C.; Buonaccorsi, G.A.; Maguire, N.C.; Hubbard Cristinacce, P.L.; Singh, D.; Vestbo, J.; Bjermer, L.; Jögi, J.; et al. Feasibility assessment of using oxygen-enhanced magnetic resonance imaging for evaluating the effect of pharmacological treatment in COPD. Eur. J. Radiol. 2014, 83, 2093-2101. [CrossRef] [PubMed]

(C) 2018 by the authors. Licensee MDPI, Basel, Switzerland. This article is an open access article distributed under the terms and conditions of the Creative Commons Attribution (CC BY) license (http:/ / creativecommons.org/licenses/by/4.0/). 